\title{
A Comprehensive Flood Event Specification and Inventory: 1930-2020 Turkey Case Study
}

\author{
Ismail Haltas ${ }^{1}$, Enes Yildirim², Fatih Oztas, Ibrahim Demir ${ }^{2}$
}

\author{
${ }^{1}$ Department of Civil and Environmental Engineering, King's College, Wilkes-Barre, Pennsylvania, USA \\ ${ }^{2}$ Department of Civil and Environmental Engineering, University of lowa, lowa City, lowa, USA \\ Corresponding Author: Ismail Haltas, ismailhaltas@kings.edu
}

\begin{abstract}
Flooding is one of the most frequent natural disasters that have significant impact on communities in terms of loss of life, direct and indirect economic losses, and disruption of daily life. Decision makers often consult flood data inventories to make more informed decisions on the development of flood mitigation plans to protect flood prone communities. A comprehensive inventory that covers multiple aspects of a flood event is critical to identify vulnerable regions, historical trends, and mitigate possible flood impacts. This study proposes an integrated flood data specification to support multi-stakeholder use cases, community-based sustainable domain specific maintenance, and crowdsourced data collection and expansion. The specification is designed based on comprehensive review of existing global and national repositories, literature, needs and requirements of stakeholders. The specification is designed to cover environmental, economic, and demographic impact, hydraulic, hydrologic, and meteorological features, and detailed location information of a flood event. As a case study, a flood event inventory was compiled for Turkey between 1930-2020 using existing national and global data sources and digitized media archives. A total of 2,101 flood events with 64 data attributes have been collected over the last 90 years. An initial statistical analysis of the inventory is also presented for the seasonal and regional characteristics of flooding in Turkey.
\end{abstract}

Keywords: flooding, flood event inventory, flood event specification, data model

This manuscript is an EarthArXiv preprint and has been submitted for possible publication in a peerreviewed journal. Please note that this has not been peer-reviewed before and is currently undergoing peer review for the first time. Subsequent versions of this manuscript may have slightly different content. If accepted, the final version of this manuscript will be available via the 'Peer-reviewed publication DOI' link on this webpage. Please feel free to contact the authors; we welcome feedback 


\section{Introduction}

Floods had a destructive impact on communities in terms of loss of lives, and direct and indirect economic losses throughout human history. Due to extreme weather conditions, urbanization, and insufficient disaster response, flood losses have been swiftly increased [1]. Changing precipitation regime as a result of climate change leads to extremes in flooding and droughts [2]. Recent studies show that the frequency of major flood events increased in many places across the world [3-5]. In 2012, floods caused \$19 billion in economic losses globally [6]. Based on climate model patterns and future scenarios, floods are expected to affect 450 million people and 430 thousand $\mathrm{km}^{2}$ of cropland by 2050 [7]. Successful flood preparedness plans require better understanding of impact of floods on communities. Therefore, flood resilience becomes crucial for communities that are vulnerable to flooding to cope with future flood events. Understanding the vulnerability of communities is possible by analyzing historical trends in flood risk and reliable projection of fatalities and losses [8]. Standardized data collection has a significant role in the context of flood resilience analysis [9]. The collection of the flood dataset should be as extensive as possible to cover many aspects of the floods to derive critical information about the risk and vulnerability.

\subsection{Flood events data in flood risk management}

The availability of flood events data is very important to understand the flood characteristics and vulnerability of an area and to improve the accuracy of the models and analyses in flood risk assessment studies. There are several studies using flood inventory data to validate or calibrate hydraulic models as well as the flood risk analyses. Observed flood characteristics such as high-water marks and flood extends are used to validate the hydraulic models in these studies. [10] validated their developed cascading flash flood guidance (CFFG) system quantitatively using the flash flood event records containing location, timing, number of casualties, and economic loss data. A study on extreme water levels [11] showed that the recorded flood water levels can be a lot higher than the estimated levels. Accordingly, they emphasize the importance of using extreme (100-year or less frequent) historical event data (e.g. high watermarks and inundation extends) as a reference for modeling extreme flood hazards [12]. Flood risk assessment can be validated by overlaying historically flooded areas with flood risk zones identified using fuzzy methods [12]. Known flood extent can be used from a historical flood event to quantitatively validate the flood susceptibility model [13]. Standard engineering practices for flood risk assessment of a new or an existing settlement require to review the flood history and characteristics of the area [13-15]. Historical flood information can also help to improve our understanding of developmental stages of various flood hazards and risks [16,17] and social, physical and economic [18] which eventually leads us to better methods and mathematical models to describe those events. Flood damage data is also frequently used to identify the flood-prone and high flood risk areas to produce flood susceptibility maps at regional scales without hydrologic or hydraulic modeling [19-21]. These statistical analyses attempt to reveal the temporal and geographical distributions and trends in the flood hazards. Another statistical analysis [22] correlates the rainfall data with the observed inundation extends and economical damages to understand the existing and future flood risk under the changing climate and urbanization conditions. Significant amount of data (regarding the cause of the flood hazard) is required to conduct hydrologic and hydraulic modeling and analysis including rainfall and stream gauge measurements. On the other hand, data regarding the consequences of the flood hazard such as the high-water marks, flood extends, or direct economic loss at flooded areas, to validate the models and analysis is very limited. Therefore, the vast majority of the produced flood hazard maps and flood risk analysis suffer from insufficient validation. Calibration of flood risk models is essential for accurate cost-benefit analysis of structural and non- 
structural flood protection measures. Challenges and findings from studies above underline the importance of flood events data in any stage of flood risk management.

\subsection{Flood inventory specification}

Comprehensiveness, accuracy, timeliness, and accessibility are the four key parameters for an efficient disaster management system [23]. Having a comprehensive flood loss inventory is essential for decisionmakers to evaluate existing policies and investigate vulnerability in communities [24,25]. Also such inventory allows for carrying out flood related analyses that can be valuable for decision-makers [26] and can be utilized for management purposes. Flood management has three main phases including preparedness, response, and recovery [27]. Particularly, a detailed flood inventory can be very helpful for the preparedness phase. Since communities do not have infinite resources, successful prioritization of regions and allocation of resources can be achieved by consulting the inventory. Consequently, an extensive flood loss inventory becomes crucial to cover these needs for best practices.

Beside costly surveys and data collection efforts, valuable supplementary data can be collected about flood events from existing data sources, archives, and media to support economic and policy practices [28]. Storing flood-related data in centralized and integrated systems using web technologies to support various aspects of the decision-making process for flood risk management and flood mitigation [29]. The centralized systems can also improve sharing data, reduce the learning curve for users, and allow scalable data analysis [30,31]. Flood loss estimates and other flood-related information are contributors to decision-making processes to improve mitigation plans and crucial input for allocating resources to help communities [32,33]. A data inventory that embraces extensive information about flooding in terms of demographic, economic, urban, and agriculture perspectives will allow decision-makers to understand historical flood trends and analyze vulnerability and flood risk for the communities. The inventory can be enabled with artificial intelligence technologies to improve delivery and accessibility of the information $[34,35]$ and used as a reference input for serious gaming platforms [36-38] to train decision-makers and the public.

Due to the lack of systematic and standardized data collection on disasters, long-term planning becomes a critical challenge for decision-makers [39]. The standardized data and information [40] is a critical need for improving hydrological data management [41], remote sensing and monitoring [42], data analytics [43], and forecast and modeling studies [44-46]. Information generated through optimized data structures can support informed decision for flood management and control [47], preparedness [48], prevention [49], recovery, and response to future flood events and can be utilized for these applications. An ideal flood event database should aim to provide information for the various aspects of the flooding so that the data specification can meet the needs of various stakeholders including decision-makers and planners. An extensive database should also allow further analysis of resilience and vulnerability, and flood hazard risk mapping in the future. Decision-makers often consult vulnerability and risk assessment to identify primary regions for resource allocation. Moreover, flood-related information should be accessible in a user-friendly interface with requiring minimal technical skills and knowledge [50]. To achieve that web-based geospatial platforms create opportunities for collecting and sharing flood event data with the community in a fast and easy way [51]. With internet technologies, the potential in flood data analytics can help interpret a flood event and serve decision-makers. It is also possible to overcome learning curves such as GIS knowledge, database knowledge for the users by taking advantage of internet 
technologies. Thus, a comprehensive visualization and communication platform [52] for the flood information can be achieved by utilizing web-based frameworks.

\subsection{Flood risk in Turkey}

Flooding is the second most significant natural disaster experienced in Turkey after the earthquakes [53]. However, number of studies investigating the flood risk in Turkey is rather limited. Most of the flood hazards in Turkey are riverine or urban type. Due to the diverse topography and geographic location of Turkey, flood hazards are observed both at the upstream of the catchments as a flash flood and the downstream as an overbank flood. Historically most significant flood events are observed along the coast of the Black Sea and Mediterranean Sea due to heavy rain along the mountains parallel to the coast. Although majority of the flood events are experienced along the coastal regions, coastal flooding in Turkey is negligible. The second most important driver for flooding is the increased streamflow due to snowmelt in the eastern mountainous region of Turkey. Black Sea, Mediterranean, and Eastern Anatolian regions of Turkey are the most prone regions to flood risk [54]. Turkish legislation does not obligate mandatory flood insurance, yet the government compensates for the economic loss of private stakeholders together with the public stakeholders if the event is classified as a natural disaster. The number of flood occurrences and the cost of damage from flooding in Turkey is increasing over time due to unplanned urbanization and land use in the upstream of the catchments and on the banks of the rivers. Therefore, the central government initiated an Integrated Flood Management approach comprising both structural and nonstructural solutions to mitigate the increasing consequences of flood events. As part of these efforts, the Turkish Disaster and Emergency Management Presidency (AFAD) together with METU Disaster Management Centre developed a platform for documentation and data analysis of various natural disasters called Turkish Disaster Data Bank (TABB) project [55]. There are earlier efforts for developing an inventory for flood events in Turkey with limited data coverage and accessibility [25, 26]. For the Republic of Turkey, there is a need for historical flood data inventory to help decision-makers for early planning [56]. Coverage of the existing flood-related databases is inadequate both for the details about the flood events and number of records. Although the early flood records in Turkey dates to the 1930's, there are only a few numbers of floods recorded between 1930 - 1955 for catastrophic flood events in major cities.

\subsection{Proposed flood event data specification and inventory}

In this study we propose a comprehensive and integrated flood event data specification to support use cases for various stakeholder in flood preparedness, response, and recovery applications. Insufficient number of flood records and lack of consistent flood event definition between agencies are the important motivations of our case study on Turkey. By accessing digitized media archives, we have collected valuable flood information and shared in accessible data formats. Proposed data repository will support studies to assess the most vulnerable districts within communities and prioritize regions to allocate limited resources. Providing a standardized flood event data specification will be instrumental for state and federal agencies to exchange data consistently for evaluating historic flood events and coping future flood events in Turkey and many developing countries.

Proposed set of specifications for flood event data inventories in multiple aspects of flooding such as meteorological, hydrological, economical, agricultural, demographical, and environmental is critical for large-scale interdisciplinary projects. The set of specifications aims to capture more details from flood events in an organized format to contribute flood risk management and planning process. The aim of the case study is compiling and updating the existing flood event inventories for Turkey and revising the 
inventory aligned with the proposed set of specifications and extending the repository with digital media archives. The updated flood events inventory is published openly for the use of government organizations, researchers, and the public.

In the following sections of the paper; details of specification and data collection process for the study are given in materials and methodology section, challenges in data collection aligned with specification development are stated along with the general flood event statistics for Turkey case study in the results and discussion section, lastly, a summary of the contribution of the study and future works are given in the conclusions section.

\section{Materials and Methodology}

\subsection{Review of existing disaster inventories and specifications}

Several flood-related and general disaster-related databases are publicly available both on global and national scales. EM-DAT, a global database on natural and technological disasters [57]; Dartmouth Flood Observatory (DFO) [58], Global unique disaster Identifier number (GLIDE) [59], Munich Reinsurance Company NatCatSERVICE Database [6]; Historical Analysis of Natural Hazards in Europe (HANZE), [60], Spatial Hazard Events and Losses Database for the United States (SHELDUS), [61] are major global databases that also include flood event data. Global disaster inventories provide flood events with a unique identifier for the disaster, date of the event, location, disaster type, economic, and demographic information. While some of them are available on a web-based environment, some of them can only be accessed with special permission from the administration. The temporal coverage of the datasets is ranging between the 1950 s to the 2000s, but most of the datasets only cover events that occurred in the last two decades.

Turkish State Meteorological Service (MGM) oversees forecasting and recording meteorological hazards including floods. MGM archives observed meteorological hazards that impact daily life or causes any loss or damage. In the MGM dataset, heavy rain and flood events are reported together as a single meteorological hazard type. MGM dataset records the events by date, place (district and province), and the damage caused. Although it provides an extensive entry of events since 1975 the details of the event consequences are limited to a set of pre-identified descriptions such as "loss on agricultural products", "damage on transportation infrastructure", etc. without any specifics or quantities. This dataset is not publicly available but shared with universities on demand for research purposes.

Recently the Turkish Disaster and Emergency Management Authority (AFAD) developed a Disaster Data Bank (TABB) which aims to archive and openly share observed hazard events including flood events [55]. TABB covers a very extensive list of natural and man-made hazard types and the data bank heavily relies on the archive of state-run Anadolu News Agency (AA) and the user uploaded data and documents. The data retrieval is a semi-automated process using data mining. TABB analysis module aims to inform a detailed list of event characteristics and risk factors ( 18 items), yet the collected and shared data is limited with the information available in the relevant notes from the news agency; therefore relatively scarce. Also, the data retrieval process makes the collected data prone to significant errors. Comparing both national and international databases, the coverage of the international scale databases for Turkey can be found significantly limited to be useful in research studies to help decision-makers to prepare for future events. EM-DAT and DFO are the commonly used international databases that covers flood-related 
information for Turkey. However, their content regarding the number of events and event attributes is also not sufficient for decision-making process.

The primary objective of these databases is capturing a general understanding of the disaster impact for communities in terms of vulnerability assessment, economic and demographic impacts, and identifying critical disaster locations. However, creating a large-scale database that is planned to cover different aspects of the disaster is a significant challenge. There is a gap for standardized disaster inventory which addresses multiple aspects of the disaster to carry out critical analysis for decision-makers. The proposed data specification is named as Flood Event Data Specification (FEDS) and the developed repository is named as Turkey Flood Inventory Dataset (TFID). Coverage of the existing databases are evaluated for data availability under demographic, hydrologic, hydraulic, meteorological, economic, environmental, and resources categories for verification purposes (Table A1).

Undoubtedly, the location of the flood event is significant to reveal flooding trend for the area. Most of the disaster databases provide detailed information (two and more data fields) about the event location. Although, demographic, economic, and environmental impact information is critical to assess accurate vulnerability analysis, most of the databases provide very limited information (one data field or no data) or no information at all. Similarly, the flood risk is another important element for disaster management, however most of the databases share little information about meteorological, hydrological, and hydraulic aspects of the flood event which leads to uncertainty in understanding the flood risk.

\subsection{Flood event data specification (FEDS) development}

An extensive survey of existing global and national disaster inventories was reviewed to inform the specification development process. Data fields are examined and categorized based on various aspects of the event characteristics including demographics, meteorology and hydrology, disaster impact and resource (See Table 1). One of the reasons for creating multiple categories is delivering disaster information to different stakeholders. It is designed for facilitating flood event data for multi-purpose applications (risk and vulnerability assessment), and creating potential use cases such as insurance premium estimations, community rating system (CRS) analysis, etc.

Table 1. Comparison of existing databases and proposed specification for data attributes

\begin{tabular}{|c|c|c|c|c|c|c|c|c|c|}
\hline \multirow[b]{2}{*}{ Data Categories } & \multicolumn{6}{|c|}{ GLOBAL } & \multicolumn{2}{|c|}{ NATIONAL (TUR) } & \multirow[b]{2}{*}{ FEDS } \\
\hline & EMDAT & DFO & SHELDUS & HANZE & Munich Re & GLIDE & TABB & MGM & \\
\hline Location & 4 & 4 & 3 & 2 & 3 & 2 & 6 & 2 & 4 \\
\hline Meteorology & no data & no data & no data & no data & no data & no data & no data & no data & 5 \\
\hline Hydraulics and Hydrology & 2 & no data & 1 & no data & no data & no data & no data & no data & 6 \\
\hline Demographic Impact & 5 & 2 & 6 & 2 & no data & no data & 14 & no data & 16 \\
\hline Economic Impact & 4 & no data & 10 & 1 & 2 & no data & 21 & 1 & 15 \\
\hline Environmental Impact & 2 & no data & no data & no data & no data & no data & no data & no data & 5 \\
\hline Resources & no data & 1 & 1 & 2 & no data & 1 & no data & 1 & 5 \\
\hline \# Attributes & 36 & 30 & 31 & 18 & 6 & 4 & 46 & 6 & 64 \\
\hline
\end{tabular}

Specification development is critical to simplify the sharing and integration of flood event information between decision-makers and local authorities. Particularly for mitigation activities, a comprehensive flood specification can allow comprehensive vulnerability and flood risk analysis. Additionally, an ideal specification should cover various aspects of flood event information to support various studies to support 
flood risk management and planning. In this study, a flood event data specification is developed to support preparedness, response, and recovery phases of flood risk management. Existing global disaster data inventories are reviewed to develop specification that is comprehensive enough to meet decision-makers' needs. Even though collecting past flood information concerning the new specification is a challenge, it is aimed to improve standardized data collection for future flood events.

Most of the current datasets store the information in one table which may create data redundancy and inefficient structure for storage. As illustrated in Figure 1, the database is divided into eight data categories namely, Core Flood Information, Location, Meteorology, Hydraulics and Hydrology, Demographic Impact, Economic Impact, Environmental Impact, and Resources. Attributes that are in the Core Flood Information category are meant to identify the flood event and set to be the mandatory fields to register a flood event into the database. The attributes within the other seven categories are set to be optional. All data tables are connected by using a unique flood event identifier.

Based on Figure 1, a data model is created to define attributes and store the relation between the data tables. One of the objectives of this study is developing a structure for the flood event data specification that allows other domain scientists to provide feedback and improve the specification in the future. Also, a web service will be developed to support accessing and updating the flood event specification. Although existing databases (Table 1) are aimed to help decision-makers understand flood events, data fields are not comprehensive enough to include different characteristics of the flood. In the following subsections, the data field categories, their explanations, and units are detailed.

The proposed database specification has 64 unique attributes for flood event entries. These attributes must be well defined so that they can be used accurately in the correct context. Also, the entries must be collected and compiled using a format that is aligned with the definition of the attributes. Although some of the date fields are clear by their names several others need a further description to put the entries into a well-defined context. In the following paragraphs, some of these attributes are described in individual data tables.

Core Flood Information: In this data table, fundamental flood information which are unique identifiers (event id, internal database id, GLIDE number), date/time (local time) information, geographic information (country, state, city), and type of flood (i.e. riverine, coastal) will be stored. These fields are identified to be the core flood information due to being covered in many archives and disaster inventories. We found that many of the disaster inventories and newspaper archives essentially store these data fields. Asian Disaster Reduction Center (ADRC) proposed a globally common Unique ID code for disasters. This identification method is accepted and promoted by several other national and international agencies such as World Bank, United Nations Development Program (UNDP), World Meteorological Organization (WHO) and was jointly launched as a new initiative called "GLIDE" [59]. In addition to an internal identifier unique to the proposed inventory, we also provided the GlideNumber identifier to support global disaster data inventory standards. Flood events usually occur after heavy rain events, and depending on the hydrologic characteristics of the basin and characteristics of the storm, there might be a delay in the order of days in the occurrence of the flood and the start of the storm. Also, some flood events continue over a couple of days. Therefore, the date of the flood events may have been reported inconsistently in the data sources. In the developed specifications the event date is recorded as day, month, and year of the event, and it is defined as the day when the flood event was first observed. Riverine floods result due to the overflow of a stream (river, creek, canal). The name of the overflowing stream is also recorded in the core flood 
information table for the riverine flood events. Overall, the core flood information table delivers when, where, and how a flood event occurs. Most archives do not provide detailed information about the other aspects of flooding such as precise location, demographics, hydrologic, economic losses, validation of sources, and hazard information. Thus, creating separate data tables which are enabled with a unique flood identifier can reduce data redundancy for future data collection efforts.

Demographic Impact
\begin{tabular}{|l} 
Flood Event ID: Integer \\
Fatalities: Integer \\
Injured: Integer \\
Missing: Integer \\
Indirect Affected: Integer \\
Displaced: Integer \\
Evacuated: Integer \\
\hline
\end{tabular}

\section{Economic Impact}

Flood Event ID: Integer Destroyed Property: Integer Total Damaged Buildings: Integer Flooded Residential: Integer Flooded Business: Integer Flooded Public Buildings: Integer Flooded Vehicles: Integer Flooded Agricultural Land: Numeric Perished Cattle: Integer Perished Ovine: Integer Perished Poultry: Integer Damaged Infrastructure: Text Total Direct Economic Loss: Numeric Direct Residential Loss: Numeric Direct Business Loss : Numeric Direct Agricultural Loss: Numeric Direct Public Loss: Numeric

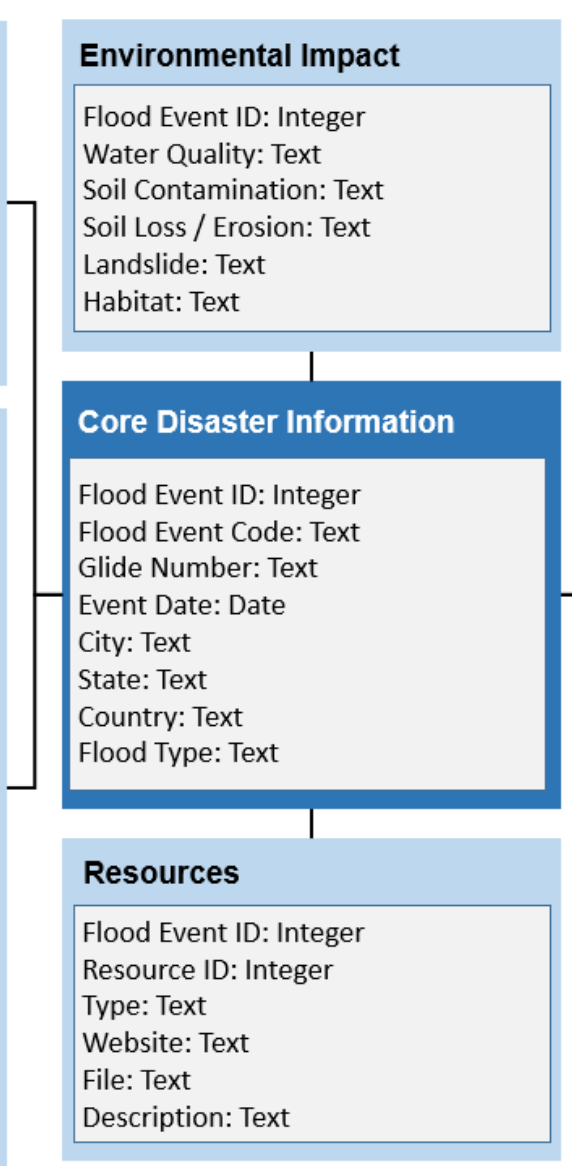

Hydraulics and Hydrology

Flood Event ID: Integer Duration: Numeric Flow Velocity: Numeric Triggering Factor: Text Frequency: Text Intensity: Text Flooded River: Text

Flood Extent Map: Geometry Flood Depth Map: Raster Flood Velocity Map: Raster Reference Point: Text Peak Discharge: Numeric Peak Discharge Time: Time Stamp Peak Water Level: Numeric Peak Water Level Time: Time Stamp Station Location: Geometry (point)

\section{Meteorology}

Flood Event ID: Integer

Reference Station: Text

Station Location: Geometry

Total Precipitation: Numeric

Precipitation Duration: Numeric

Total Precipitation Map : Raster

Location
\begin{tabular}{|l} 
Flood Event ID: Integer \\
District: Text \\
Vicinity: Text \\
Area: Geometry (Polygon) \\
Location: Geometry (Point)
\end{tabular}

Figure 1. Structure of the proposed database specification and data model

Location: The core flood information table has an identifying location field at city level for the flooded site. However, city level location information may not be sufficient to make a detailed analysis in certain cases (i.e. detailed vulnerability mapping for a community). For this purpose, the location table is created with geospatial file support to provide definite information for the flood site. In some cases, impacted vicinity information can be more valuable for site-specific decisions. Therefore, large scale to small scale site information is targeted to provide a detailed location table.

Hydraulics-Hydrology and Meteorology: Two separate tables for hydraulics-hydrology and meteorology are particularly created to store certain characteristics of a flood event such as precipitation, peak flood discharge, velocity, flood map, triggering factors (snow melt, heavy rainfall, debris accumulation) measurement locations for the sites. Flood frequency which is a type of measure to show how severe the 
flood event is also included in the database specification to support decision-making processes. The main inputs for quantifying flood frequency are discharge and statistical occurrence of the discharge. These parameters are the most important contributing factors for flooding in urban and rural areas. Thus, the parameters enhance the better understanding of an event from the hydraulics, hydrology, and meteorology point of view.

Demographic Impact: The demographic data table is aimed to support vulnerability and resilience analysis at flooded sites. The number of fatalities, injuries, affected and displaced people are strong indicators of flood vulnerability. Therefore, a flood inventory that keeps the information about this demographic information can be a future reference for vulnerability assessment for the specific sites.

Economic Impact: Economic losses in a flood event is another critical indicator of flood vulnerability for communities. Economic loss can be classified into four main aspects namely, residential, commercial, agricultural, and public losses. Economy-related data table can be an input for flood vulnerability assessment. In the data sources the direct economic loss is reported for various risk factors such as the number of buildings, cars, livestock, or area of flooded agricultural land, etc. Some data sources also report the estimated total direct economic loss in monetary amounts. All these economic loss items are included in the inventory table as individual attributes whenever reported.

Environmental Impact: Environmental impact table is another contributing input for flood risk and vulnerability assessment. Water quality problems (i.e. drinking water contamination), soil contamination, erosion, and landslide are primarily important impacts of a flood event on environment. These factors can directly affect communities by creating health problems, reducing agricultural productivity, and disruption of services. In addition, habitat is also included to record environmental impact of a flood event on certain species.

Resources: A flood event data may depend of many different sources such as global or national inventories, technical reports, newspaper archives, etc. Validation of the gathered flood data is crucial for the accuracy of any flood data inventory. The resources table is designed to provide validation of the attributes in the flood data inventories. By making a cross-reference check, collected flood information can be verified, and the data can be used for accurate decisions for flood mitigation purposes. Multiple reference types (photo, video, text), websites, and description of an event can be defined in the resources table.

\subsection{Flood event data collection process}

In many disaster inventories "a disaster event" is defined and included according to various threshold criteria. Some inventories only include events with a minimum number of death tolls and/or economic loss, or if a national emergency is announced. For instance, EM-DAT considers events with 10 or more fatalities and 100 or more injuries to be entered in its disaster inventory [57]. In this study, a flood event is defined as any flood that is reported by local authorities, agencies, and media whether it results in any death or economic loss or just a temporary disruption in daily life. The inclusion of flood events is not limited to the losses caused by the events to have a comprehensive inventory. So that the developed inventory not only documents observed losses but also includes potential flood risks that can result in a loss in the future occurrences. 
Data collection is a significant part of inventory development. To achieve the most comprehensive, accurate, and updated inventory for flood events in Turkey, all the available national and international data sources are reviewed and processed (Table 2). This process was not straightforward as the available data sources were not homogenous in terms of content, format, and accessibility as discussed earlier. On the other hand, the process is conducted as systematically as possible to eliminate any mistakes or bias in the final output as well as to develop a methodology that can be applied to similar cases in other studies and inventory development efforts. The process is summarized in the flowchart given in Figure 2 and the process steps are explained in the following paragraphs.

Table 2. Comparison of existing databases and proposed inventory for data coverage

\begin{tabular}{|c|c|c|c|c|c|c|c|c|c|}
\hline & \multicolumn{6}{|c|}{ GLOBAL } & \multicolumn{2}{|c|}{ NATIONAL (TUR) } & PROPOSED \\
\hline Data Summary & EMDAT & DFO & SHELDUS & HANZE & Munich $\mathbf{R e}$ & GLIDE & TABB & MGM & TFID \\
\hline Date Range (Global) & $1904-2020$ & $1988-2020$ & 1960-2018 & $1870-2016$ & $1980-2018$ & $1967-2020$ & $\mathrm{~N} / \mathrm{A}$ & $\mathrm{N} / \mathrm{A}$ & $\mathrm{N} / \mathrm{A}$ \\
\hline \# Records (Global) & 10,255 & 4,941 & 104,324 & 1,564 & 5,997 & 2,570 & $\mathrm{~N} / \mathrm{A}$ & $\mathrm{N} / \mathrm{A}$ & $\mathrm{N} / \mathrm{A}$ \\
\hline Date Range (TUR) & $1948-2020$ & $1988-2020$ & $\mathrm{~N} / \mathrm{A}$ & $\mathrm{N} / \mathrm{A}$ & $1980-2018$ & 1998-2009 & $1940-2016$ & $1975-2015$ & $1930-2020$ \\
\hline \# Records (TUR) & 66 & 47 & 0 & 0 & 59 & 10 & 782 & 36 & 2,101 \\
\hline
\end{tabular}

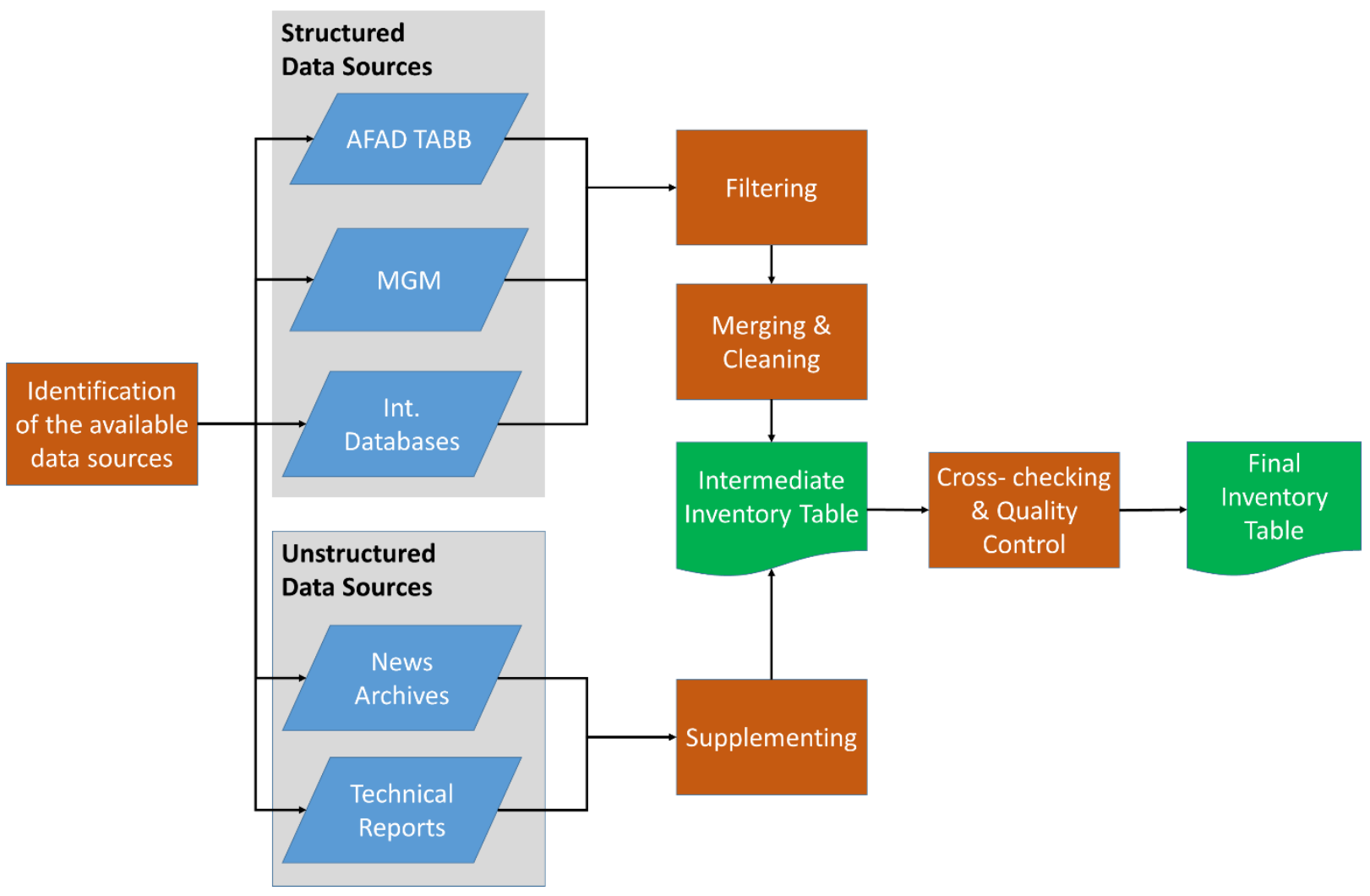

Figure 2. Steps in flood events data inventory development process

The data collection process starts with the identification and review of the existing data sources. A quick search in the relevant journals and the gray literature revealed the main data sources for flood events in Turkey. TABB, MGM, and several international disaster databases are available structured data sources for Turkey that are identified and utilized in the study. There are also non-structured individual data 
sources for flood events in the form of articles from news agencies, blog articles and technical reports. Although the structured data sources are relatively easier to collect, combine, and process, the nonstructured data sources cannot be ignored as they provide comprehensive coverage and usually detailed insight regarding the event.

\section{Processing flood event datasets}

In this systematic approach, the structured data sources are used as a starting point to identify the flood events. Event date and location are two primary attributes identifying any flood event. All three sources are multi-hazard databases which include not only the flood hazard but other meteorological and nonmeteorological hazards such as hail, storm, avalanche, earthquake, landslide, etc. Therefore, the floodrelated hazard events are filtered and collected as data tables. These data tables are very similar to each other and customary in the sense that the columns (horizontal dimension) identify the event attributes, and rows (vertical dimension) identify each event entry in the table.

In the next step, these data tables from different sources are merged into a single data table. Merging datasets is one of the most challenging steps in the process as each table has its own custom attributes and even definitions for similar attributes may have nuances. In merging attributes, it is aimed to be inclusive to preserve as detailed information as possible. The observed variation in the attribute definitions from different data sources necessitated to develop a standard definition in this study for some of the complex attributes such as event date. Merging the flood events records was also challenging as there were several overlapping events listed under different data tables. The ambiguity and inconsistency in the location information made this merge further complicated. Not all the data sources use the same level of detail (or scale) for the location attribute. For example, one data source provides only the name of the city as the location of the event whereas the other source provides the name of the district. Also, there were changes in the location names as local governmental boundaries changed over time. Furthermore, the same storm may result in flood events in different districts of the same city on the same date, so it is hard to identify if these two events are identical or different. Also, the definition of the event date can cause inconsistency. Some data sources may report the start of the heavy rain or storm as the date of the event whereas another source may note the date of the observed flood event which may be one or a couple days later than the start of the storm. Merging such events require additional considerations and manual processing. In the merging process, some of the attributes are redefined and the data entries are translated according to the new definitions. Then the events are sorted in chronological order and the overlapping events are consolidated resulting in an intermediate inventory table. Since it is aimed to be inclusive in terms of attributes and some of the data tables had very scarce event details, the resulting intermediate inventory table was not fully filled. The international databases were of little use since they report only disasters with significant consequences that were mostly covered in the national inventories with greater event details.

\section{Supplementary data collection and quality control}

The missing fields in the intermediate inventory table are supplemented with the information collected from online archives of news articles and technical reports. This step was the most tedious and timeconsuming part in the data collection process. The flood events are searched online both in search engines (i.e. Google) and the online archive of the Turkish newspapers (i.e. Milliyet). The keywords for these searches were the date and the location of the event. Each search usually results in multiple articles based on one or more different news agencies. These articles are manually scanned to extract the relevant 
information for the attributes of the inventory table. Information in the multiple articles is cross-checked and compared to the available values in the intermediate inventory table.

All flood events are searched in the news articles for cross-checking and quality control. There are mainly two possible sources of error in the compiled dataset; errors in the data sources and errors produced during the compilation process. Errors in the source of the data can be due to the collection error or processing of the original information by the data compiler (TABB, MGM, news organization). It is hard (in some cases impossible) to identify or correct such errors, but any event with multiple sources of data is cross-checked to verify the information before including in the final inventory table. Events with multiple data sources are relatively rare especially for events older than a couple of decades. In the case of discrepancy in the data sources for the same event, information from the news agency overwrites the TABB, and TABB overwrites the MGM because the depth of details in the event report is almost always in this order.

Most of the data collection and compilation effort in this study is conducted from various sources manually by several researchers and volunteers. Therefore, the prepared data set is prone to human error. Unlike the inherited errors, identifying and correcting errors produced during the compilation process is possible. To eliminate compilation errors in the inventory table, a rigorous internal quality control process is conducted through double-checking and validation of the entries with the original data sources. Therefore, any risk of error produced during the compilation process is minimized.

\subsection{Turkey flood inventory database (TFID) case study}

The proposed database specifications, FEDS is applied to the compiled flood events data for Turkey to develop a Turkey Flood Inventory Database. The collected flood events data is rigorously analyzed in alignment with the provided definitions of the event attributes. Some of the data field definitions are interpreted within the context of flood events data in Turkey as follows.

Every event in the inventory is recorded with province and district information. For events with more precise location information, the vicinity of the event is also recorded. For mapping purposes, events are also assigned a point geometry (coordinate) data. The coordinates default to the district center for events without precise location (vicinity) information. For events with vicinity information, the coordinates are manually set according to the available location details.

Fatality numbers in Turkey usually rely on the official records therefore expected to be accurate. In a catastrophic flood event with several casualties, fatality numbers reported initially may not reflect the actual numbers as the official records do not count people missing after a flood as death until the missing body is found, which may take several days or even weeks. Therefore, conflicting numbers reported in the news articles are consolidated with the most recent numbers. Numbers of injuries are rarely reported in the data sources, but they are included in the inventory table whenever reported. The number of people evacuated or displaced are relatively less accurate, especially for events impacting large residential areas as they are usually based on calculated estimates.

Although some of the reported direct economic impact values (destroyed property, flooded cars etc.) are relatively precise, most of the time they are reported as approximate numbers even in the orders of magnitudes (i.e. more than a hundred cows perished, tens of cars flooded, etc.). Therefore, they are also 
reported as a metadata file in the resource table accordingly. The total direct economic loss values are recorded into the inventory table without applying any inflation adjustment.

\section{Results and Discussion}

In this section, results are summarized for specification and inventory development, and data collection efforts. A detailed summary and analysis of flood event data inventory for Turkey is provided with spatial and temporal trends, and some interesting findings from data.

\subsection{Specification development}

In this study, a data specification for flood events is developed and shared on GitHub Platform. The purpose of the specification development is providing fundamental information to decision-makers and allowing them to carry out multiple flood-related analyses to improve decisions on flood resilience for their communities. Also, the specification is aimed at standardized data sharing and cooperation between various stakeholders for flood management activities at mitigation and preparedness phases. Thus, the specification will support data interoperability for exchanging information on flood events. Developed specification is shared in various formats (sql, json, $\mathrm{xml}$ ) to allow researchers to easily adapt in their applications and provide feedback. A web service based on the specification will allow access to both existing datasets and specification for adding new flood events or download recorded events. SQL data format allows recreating the database for internal and private applications of the specification. XML data format standardizes the data and allows reproducible research, ease verification of the attributes, and data sharing.

One of the goals for our study is to propose a standard specification for the flood event datasets to support future data collection efforts. Data standardization is critical to allow large-scale data integration and analytics, and enhance collaborative research, and ease to access existing datasets or future datasets. In Table A2 in the appendix section, details of attributes for specification tables is summarized. ISO (International Organization for Standardization) codes for countries and cities and internationally accepted units for hydrological measurements are selected for metadata.

Flood plain managers and state officials responsible with flood response often need extensive data to analyze flood risk and vulnerability for their area of responsibility. The proposed specification allows carrying out vulnerability and risk analysis by providing data fields for demographics, hydrologic, hazard, and financial aspects of the flood event. The specification designed to support real-time data analytics applications on web-based systems by providing standardized data formats through web services.

To achieve international interoperability, UTF8 language support is implemented in the specification development. Since Turkey was selected as a case study, data fields were recorded in Turkish from many of the data sources such as newspaper archives and local databases. All the data fields are defined in English to support the internalization of the specification. The sample data structures (sql, $\mathrm{xml}, \mathrm{json}$ ) are also created with UTF8 support to collect data in any international character set. Because data API (Application Programming Interface) is becoming widespread in many domains, a future data API on flood events can be used to create a flood event inventory by using the proposed specification for flood event data format. 


\subsection{Summary of Turkey flood inventory database}

Many databases, datasets, technical reports, and news articles were reviewed from several sources, such as TABB, MGM, EM-DAT, DFO, GLIDE, local and national news archives. Figure 3 shows the time range of data availability for each dataset. TABB has largest number of events and contains data on events date, location, number of casualties and fatalities, and description of events. We started by compiling and evaluating the flood events and descriptions from published reports on TABB, covering the period from 1940 to 2017. In total 2,101 records were identified with details of each flood event that occurred across the country along with its location, duration, fatalities, mortalities, type of destruction, economic damages, and descriptions. 891 of 2,101 events were adopted from TABB and MGM datasets. In total, 691 flood events were analyzed from national and local press articles.

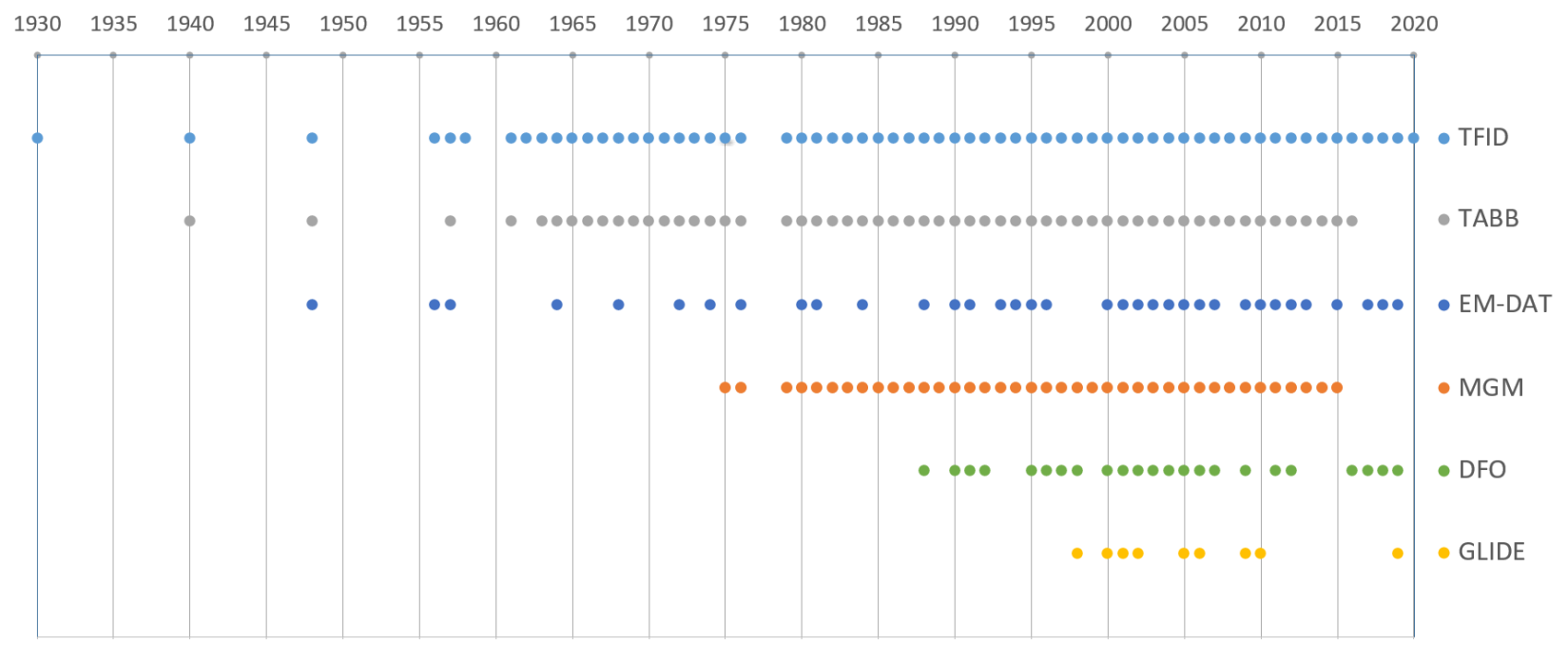

Figure 3. Time range and availability of the datasets

Summary statistics on flood events and the consequential losses are derived using the TFID. There are 2,101 events recorded in the database which covers 90 years from 1930 until the mid of 2020. The distribution of the events over the coverage period in 10-year intervals is plotted on the frequency plot in a logarithmic scale together with the population trend of Turkey. Figure 4 shows that the number of events in the flood inventory increase exponentially and the population trend line is aligned with this increase. A significant increase is observed after the 1980's probably because of the digitized recording of events and widespread use of the internet.

Out of 2,101 events, 206 of them reported the loss of life which corresponds to about $9.8 \%$ of the total number of events. Similarly, the number of events with flooded units (buildings) corresponds to $25.8 \%$ of the total number of events. The direct economic losses are only reported in $2.7 \%$ of the events, which is considered significantly low as floods are usually expected to result in some direct economic loss. Also in Table 3, the "Total Loss" column shows the total amount of loss for the corresponding risk factor, such as the total number of damaged cars are reported as 1485, and the total area of flooded agricultural land is reported as 1736 square kilometers. The "Loss Per Event" column shows the average amount of loss per event on the corresponding risk factor. For example, the total number of perished cattle is reported as 2,504 in 34 flood events; therefore, there are on average 73.6 cattle perished per reported event. 


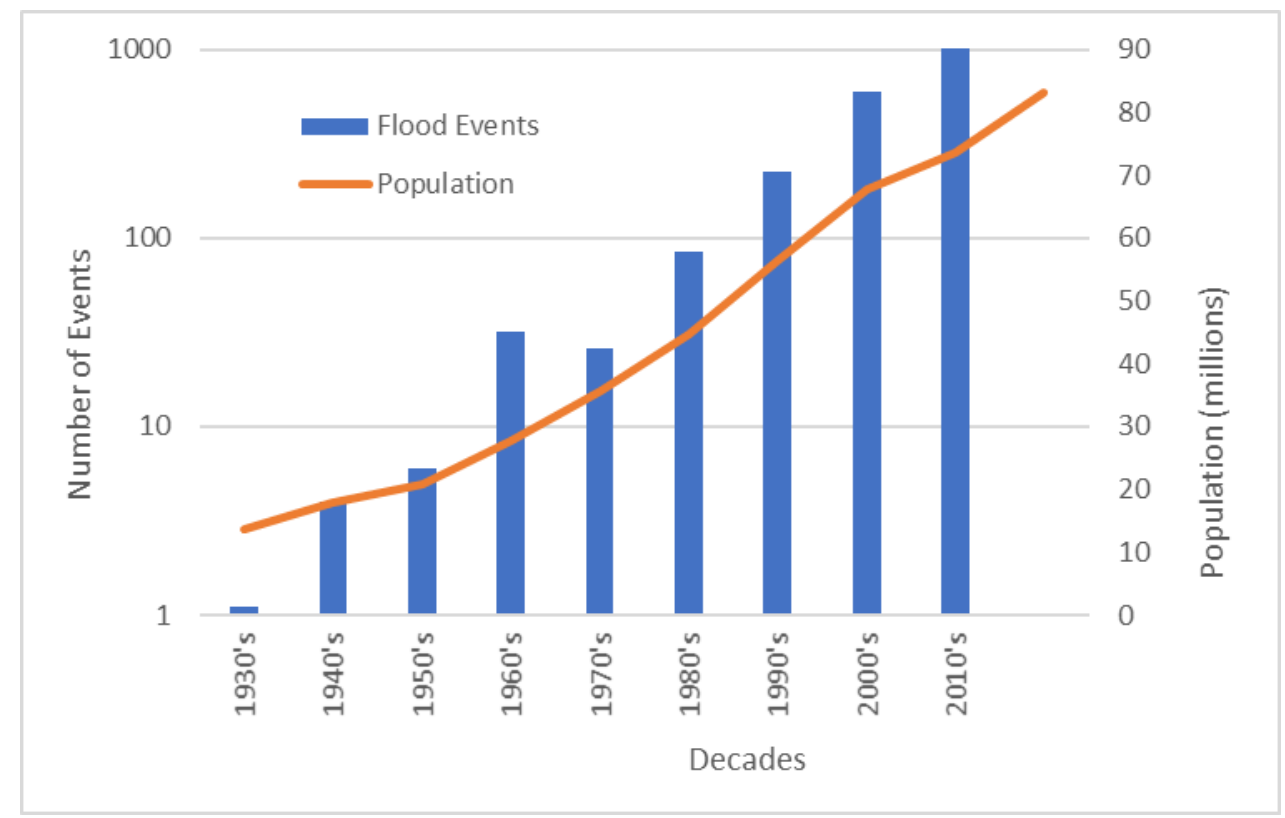

Figure 4. The number of flood events by 10-year interval between year $1930-2020$

Turkey is divided into 81 provinces and 973 judicial districts. At least one flood event is reported in each province and 545 districts. The number of flood events for provinces with more than 30 events is shown on the frequency plot (Figure 5). Most of the flood events are reported overwhelmingly in Istanbul which is a highly urbanized (5900/sq. $\mathrm{km}$ ) major metropolitan province in Turkey with over 15.5 million population. Although the average annual precipitation of Istanbul is $817 \mathrm{~mm}$ which is only $30 \%$ higher than Turkey's annual average, the record high flood events suggest that the flood management infrastructure is inadequate for the level of urbanization within the province.

Table 3. Summary of Losses due to Flood Events in Turkey 1930-2020

\begin{tabular}{|l|r|r|r|r|}
\hline Risk Factor & \# Events & Ratio (\%) & Total Loss & Loss per Event \\
\hline Fatality & 206 & 9.8 & 1,026 & 4.98 \\
\hline Injury & 79 & 3.8 & 402 & 5.09 \\
\hline Flooded Unit & 539 & 25.8 & 64,930 & 120.46 \\
\hline Destroyed Property & 70 & 3.3 & 709 & 10.13 \\
\hline Flooded Vehicle & 48 & 2.3 & 1,485 & 30.94 \\
\hline Perished Cattle & 34 & 1.6 & 2,504 & 73.65 \\
\hline Perished Ovine & 54 & 2.6 & 14,123 & 261.54 \\
\hline Flooded Agri. Land (sq. km) & 71 & 3.4 & 1,736 & 24.45 \\
\hline Direct Economic Loss (M TL) & 56 & 2.7 & 2,160 & 38.57 \\
\hline
\end{tabular}




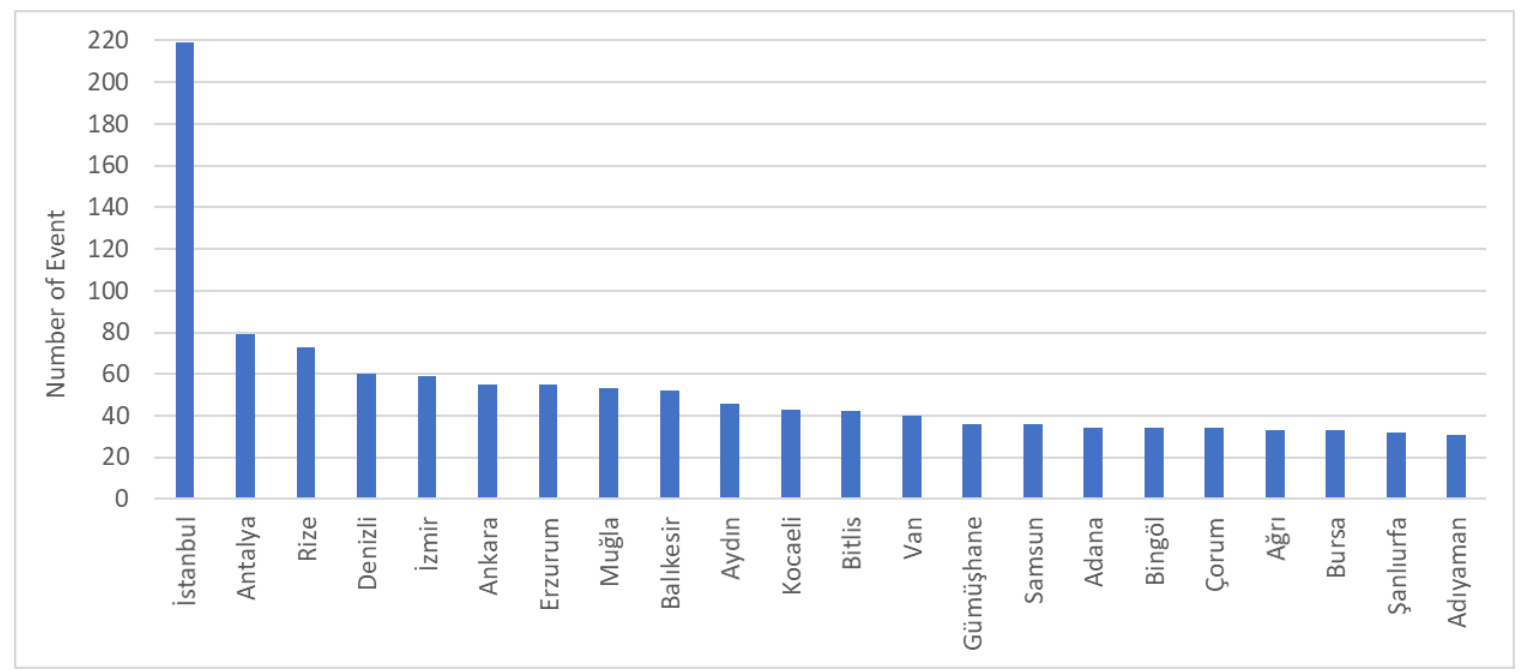

Figure 5. The total number of flood events by province between year $1930-2020$

Similarly, the number of flood events for districts with more than 15 events is shown in Figure 6 . The first two districts with the highest number of flood events are from Rize province. Pazar and Çayeli are located along the coast and on the Black Sea mountains range. The average annual precipitation of Rize is about $2,300 \mathrm{~mm}$ which is 3.7 times the average annual precipitation of Turkey. Although sparsely populated (90$280 / \mathrm{sq} . \mathrm{km}$ ) and not very urbanized, due to the very heavy rain throughout the year, the observed number of flood events for Pazar and Çayeli is not unexpected.

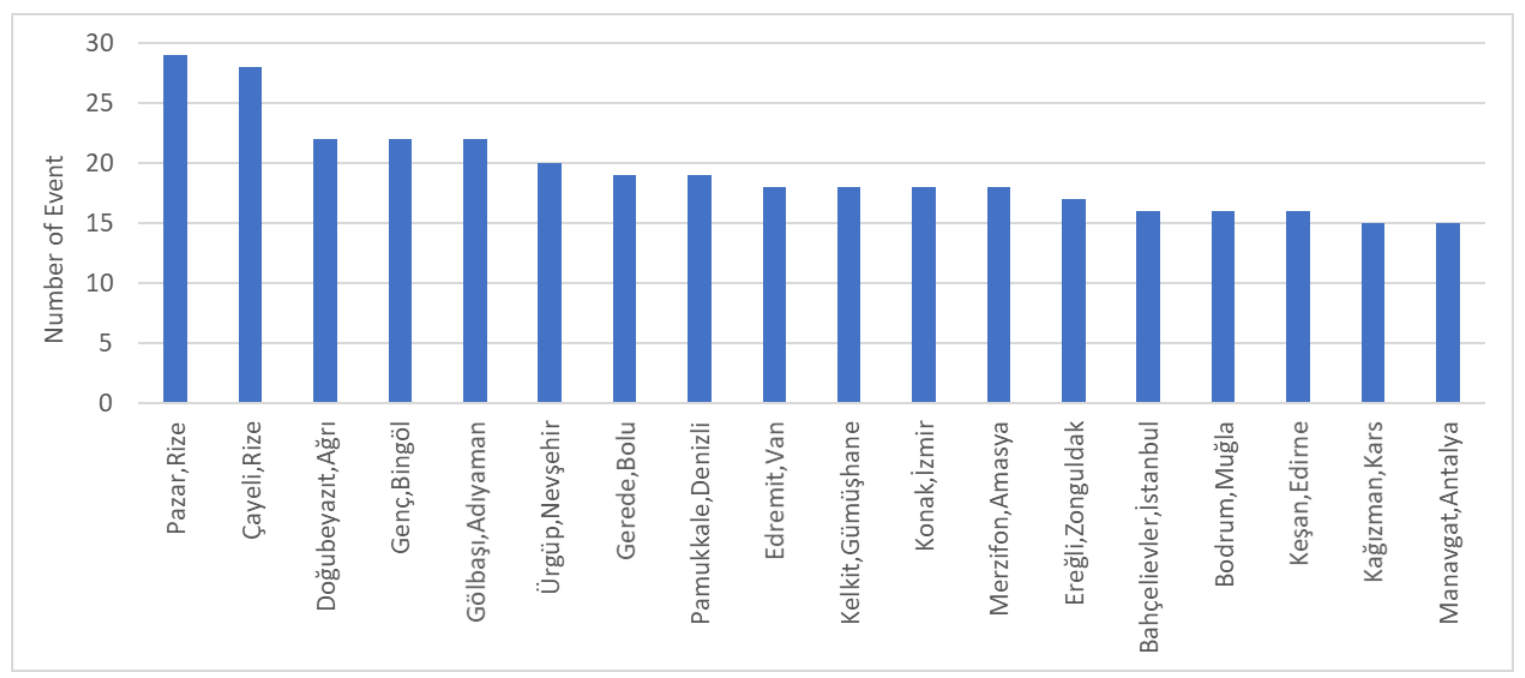

Figure 6. The total number of flood events by district between year 1930 - 2020 


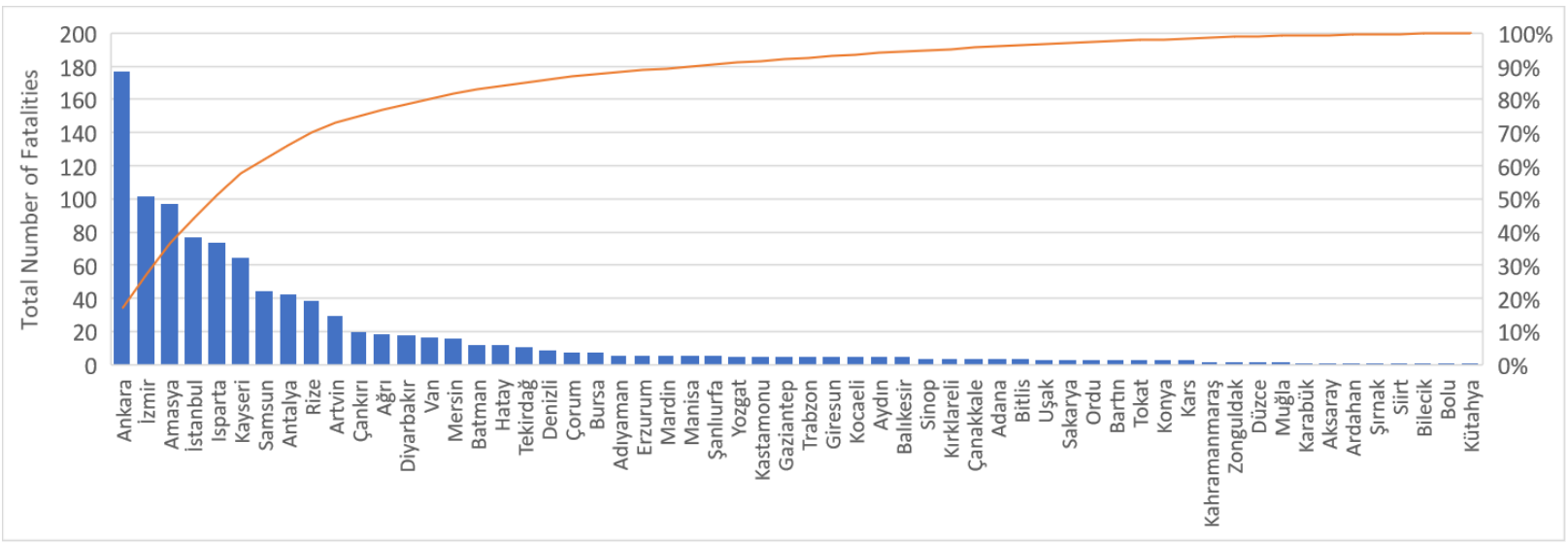

Figure 7. The total number of flood fatalities by province between year 1930 - 2020

Flood events frequency plots given in Figure 5 and Figure 6 provides an overview of flood vulnerability across Turkey. The fatality frequency plot given in Figure 7 may not be an accurate measure to inform the current vulnerability of provinces as the data is skewed by catastrophic events as listed in Table 3 where the cause of the flood is most likely mitigated after the events. According to Table 3 , the fatality rate is 4.98 per fatal flood events or 0.49 per any flood events. In a similar study for Greece [62] the fatality rate per fatal flood events is found to be 2.85 . The distribution of the total fatalities across provinces is plotted on the frequency plot given in Figure 7. The Pareto line in Figure 7 shows that $50 \%$ of the total death toll is from 5 provinces (out of 81 provinces in Turkey) with highest number of fatalities, and $90 \%$ of the total death toll is from the 25 provinces with highest number of fatalities. The record high fatality numbers for Ankara is due to a single catastrophic flash flooding along Hatip Creek on September 11, 1957, which claimed 156 human lives. There are similar flood events with high death tolls in the recent history of Turkey as listed in Table 4. In Figure 8, number of fatalities and events distribution is also demonstrated. Overall, number of flood events shows increasing trends in the communities of Turkey. Although, high fatalities were observed due to extreme events over the past 90 years, fatalities relatively decreased. Seasonal distribution of the flood event along with the monthly average precipitation is shared in Figure 9. Although average precipitation is lower during late spring and summer, number of events are higher compared to other seasons. Snowmelt, flash flooding and inadequate infrastructure can be two primary reason why this trend is observed.

Table 4. Catastrophic flood events with high (>30) fatality numbers in Turkey 1930-2020

\begin{tabular}{|l|l|l|r|}
\hline Event Date & District & Province & Fatality \\
\hline $1957-09-11$ & Çankaya & Ankara & 165 \\
\hline $1948-06-03$ & Suluova & Amasya & 92 \\
\hline $1995-07-13$ & Senirkent & Isparta & 74 \\
\hline $1995-11-04$ & Karşıyaka & İzmir & 61 \\
\hline $1980-03-28$ & Develi & Kayseri & 60 \\
\hline $1930-10-24$ & Konak & İzmir & 40 \\
\hline $2009-09-08$ & Silivri & İstanbul & 31 \\
\hline
\end{tabular}




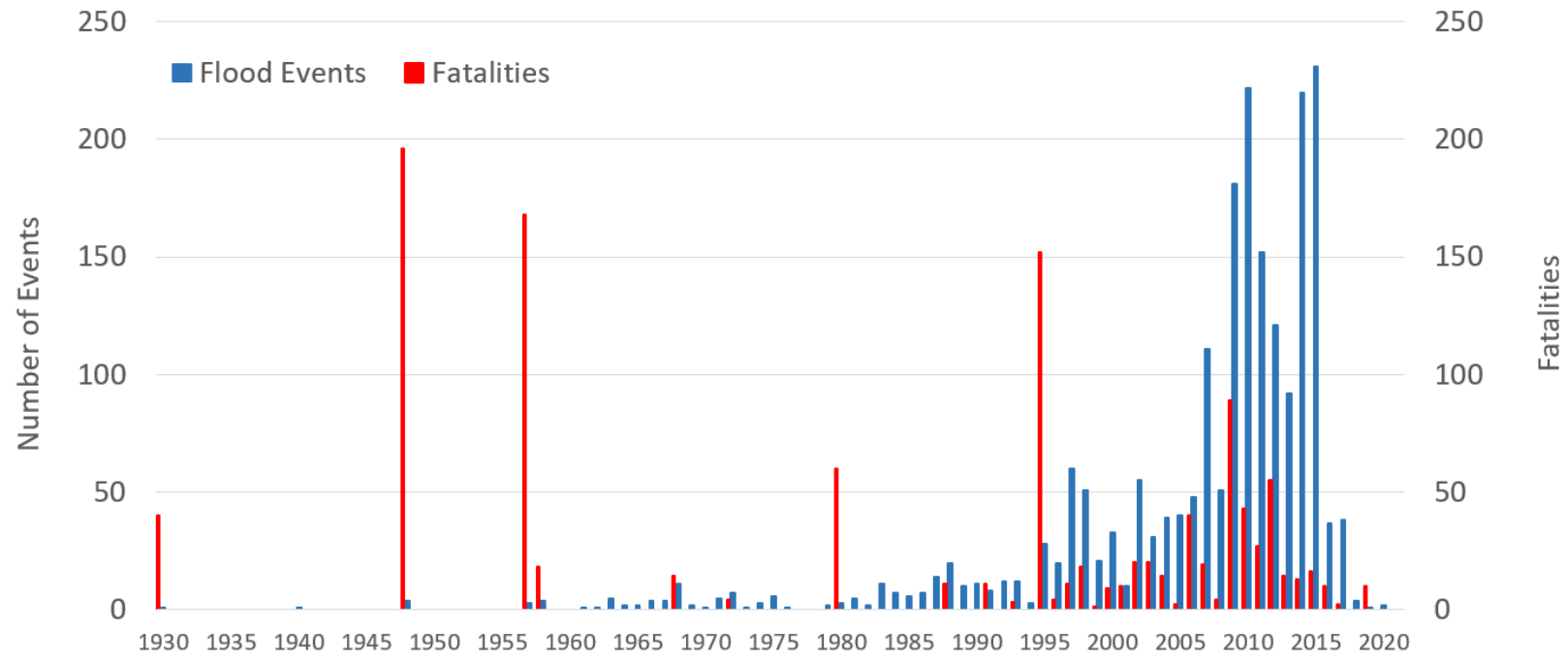

Figure 8 . The total number of flood events and fatalities per year between $1930-2020$

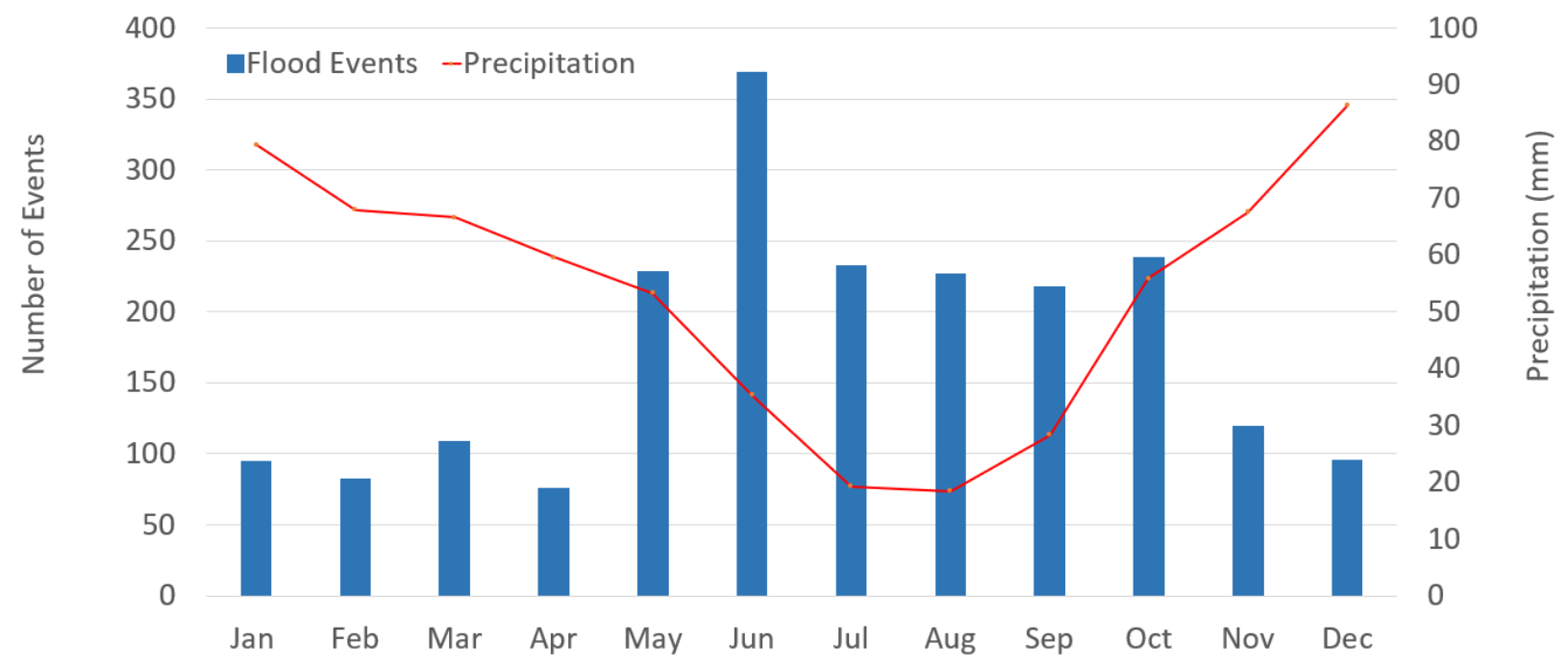

Figure 9. Seasonal distribution of flood events and monthly average precipitation between $1930-2020$

In Figure 10 and Figure 11, geospatial distribution of the flood events and fatalities are illustrated in district level. Although, flood events show homogenous distribution across to Turkey, some of the districts experienced more flood events compared to other regions. Figure 11 shows that the majority of the deadliest flood events are observed in coastal regions of Turkey. 


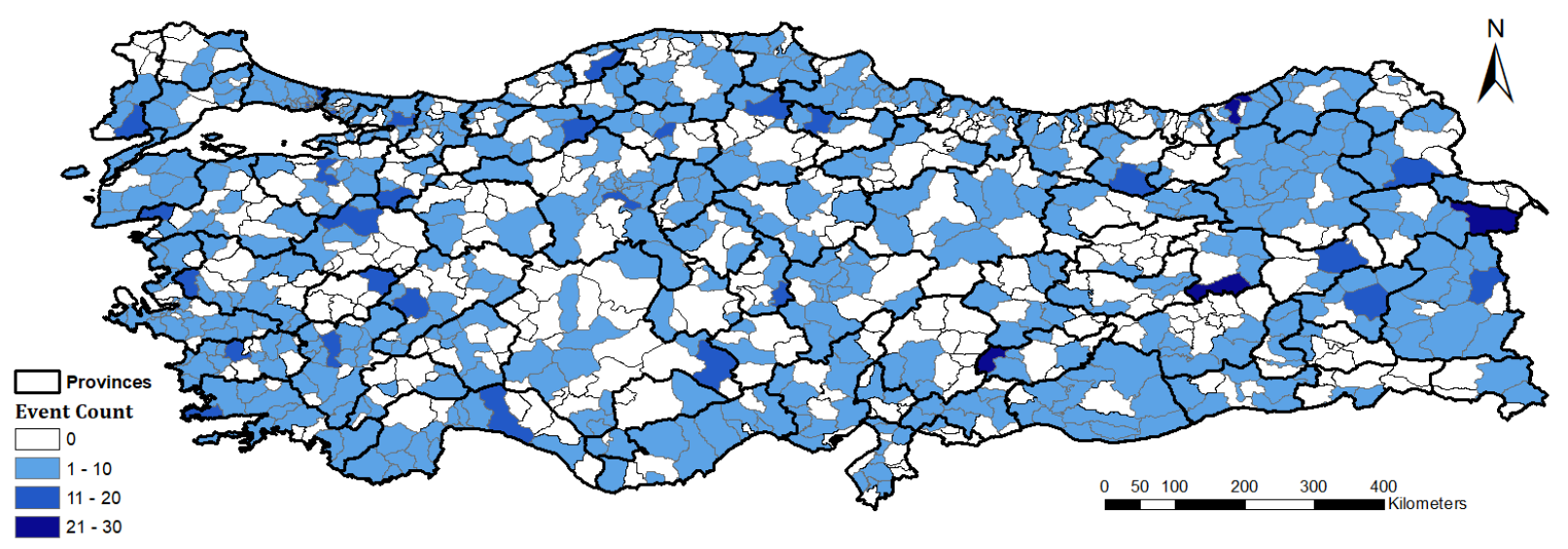

Figure 10. The total number of flood events by district between year $1930-2020$

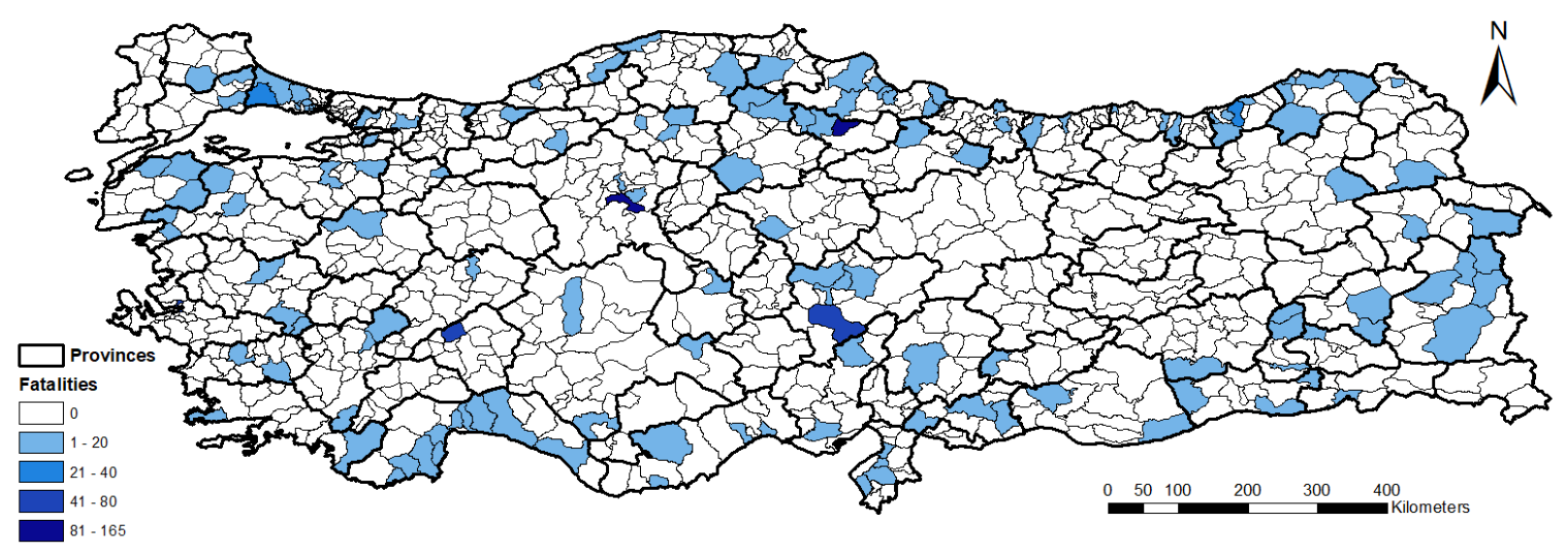

Figure 11. The total number of fatalities by district between year $1930-2020$

\subsection{Data limitations and challenges}

The absence of a systematic flood event and damage survey and data collection program undermines both the accuracy and precision of the available data. Overall, the accuracy of the event location, date, and a few flood-risk factors (such as fatality) is considered acceptable since they are relatively easy to identify and quantify as they are commonly reported by the official data sources. For most of the flood risk factors such as the number of flooded units, perished livestock, or total direct economic loss both accuracy and precision reduce significantly as these figures depend on loss claims as well as expert evaluations. Since flood insurance is not mandatory in Turkey, flood insurance claims are very rare. Any loss reported in the news articles usually relies on either the initial onsite observation of the officials, the news reporter, or people affected by the event, which results in subjective quantification of these values.

Although the compilation process for the developed inventory for Turkey, TFID, is carried out rigorously with intensive manual data processing and quality controls, there are still various limitations of the inventory. These limitations are mainly due to the insufficiencies, incompleteness, and inconsistencies of the reported flood events by the main sources. One of the limitations of the inventory is the reported 
direct economic loss values. It can be seen by the $2.7 \%$ ratio of the number of events with a reported direct economic loss to the total number of events in Table 3. Any significant flood event is expected to result in some direct economic loss but only a small fraction of the events reports the direct economic loss. For the individual events with a reported direct economic loss, the reported values still can be valuable information. This limitation is not as obvious in the other risk factors such as perished cattle, damaged cars, flooded agricultural lands, etc. But still loss figures on these risk factors are prone to lack of precision as they are commonly reported in the order of magnitudes. The most precise values reported in the inventory data table are expected to be for the fatalities since they are rigorously investigated, recorded, and reported by the government agencies. Above-mentioned accuracy and precision issues introduce a certain level of uncertainty into any statistics derived based on this inventory database.

\section{Conclusions}

In this study, a data specification for flood events and a case study for Turkey on historical flood data collection are presented. The specification is designed to support data collection on various aspects of a flood event for flood mitigation and planning purposes. Eight global and national disaster databases are thoughtfully evaluated, and a comprehensive specification is designed by considering various flood related analysis and applications. Although the proposed specification defines the attributes for core flood event data and critical characteristics of the flooding, it can be further expanded to support other use cases not supported with the current design.

Community involvement is critical for keeping the specification up-to-date and sustainable in the long run. In some cases, media archives might not be able to cover all aspects of flood or might not provide the most accurate information. Researchers and local communities can provide new or updated information about the flood event. It is possible to check and improve data quality by using crowdsourcing and citizen science approaches and automated evaluation of media archives. The proposed specification will be disseminated through hydrological and flood related communities (CUAHSI, NSF EarthCube, NSF Big Data Hubs) and organizations (FEMA, ASFPM), and flood inventory will be presented to Turkish academia and government organizations (MGM, TABB) using formal channels.

As a case study, an extensive data collection effort is organized to gather information on 2,101 flood events for Turkey. Besides existing, global, and national databases, newspaper archives are examined to populate the database as well. A preliminary analysis of the compiled data provided several statistical inferences on the flood characteristics in Turkey. The analysis shows that the number of flood events increased exponentially closely following the linear population increase during the 90 years of the study period. This trend can be related both to increased urbanization as well as widespread use of a digitized recording of flood events over time. On average one out of ten flood events resulted in the loss of human lives and the average number of fatalities per fatal event is 4.98 which is almost twice the flood fatality rate reported for the neighboring country Greece. The number of events is higher between late Spring and early Fall which could be associated with flash flooding, snowmelt, and inadequate infrastructure of flooded areas. The record high flood events are reported either in densely populated metropolitan areas with an average (of Turkey) precipitation values or sparsely populated coastal areas with significantly higher precipitation values. 


\section{Availability of Specification and Inventory}

The proposed Flood Events Data Specification (FEDS) and Turkey Flood Event Inventory Database (TFID) is made available freely in different formats (sql, $\mathrm{xml}$, json, $\mathrm{xlsx}, \mathrm{csv}$ ) with sample usage examples at the following repository:

https://github.com/uihilab/Flood-Event-Data-Specification

\section{Acknowledgments}

Data collection effort in this research study is partially funded by the Scientific and Technological Research Council of Turkey (TÜBITAK) through Grant No 111Y281. We also like to thank Mr. Kemal H. Çeliktürk and Mr. Nedim Bitim for their contribution to the inventory search.

\section{References}

[1] H. Wu, R.F. Adler, Y. Hong, Y. Tian, F. Policelli, Evaluation of Global Flood Detection Using Satellite-Based Rainfall and a Hydrologic Model, J. Hydrometeorol. 13 (2012) 1268-1284. https://doi.org/10.1175/JHM-D-11-087.1.

[2] K.E. Trenberth, Changes in precipitation with climate change, Clim. Res. (2011). https://doi.org/10.3354/cr00953.

[3] Y. Hirabayashi, S. Kanae, S. Emori, T. Oki, M. Kimoto, Global projections of changing risks of floods and droughts in a changing climate, Hydrol. Sci. J. (2008). https://doi.org/10.1623/hysj.53.4.754.

[4] Y. Hirabayashi, R. Mahendran, S. Koirala, L. Konoshima, D. Yamazaki, S. Watanabe, H. Kim, S. Kanae, Global flood risk under climate change, Nat. Clim. Chang. (2013). https://doi.org/10.1038/nclimate1911.

[5] P.C.D. Milly, R.T. Wetherald, K.A. Dunne, T.L. Delworth, Increasing risk of great floods in a changing climate, Nature. (2002). https://doi.org/10.1038/415514a.

[6] Munich RE, Data on natural disasters since 1980 Munich Re's NatCatSERVICE, (n.d.). https://www.munichre.com/en/solutions/for-industry-clients/natcatservice.html.

[7] N.W. Arnell, S.N. Gosling, The impacts of climate change on river flood risk at the global scale, Clim. Change. (2016). https://doi.org/10.1007/s10584-014-1084-5.

[8] B. Jongman, H.C. Winsemius, J.C.J.H. Aerts, E. Coughlan De Perez, M.K. Van Aalst, W. Kron, P.J. Ward, Declining vulnerability to river floods and the global benefits of adaptation, Proc. Natl. Acad. Sci. U. S. A. (2015). https://doi.org/10.1073/pnas.1414439112.

[9] K. V. Nguyen, H. James, Measuring household resilience to floods: A case study in the Vietnamese Mekong River Delta, Ecol. Soc. (2013). https://doi.org/10.5751/ES-05427-180313.

[10] Z. Zeng, G. Tang, D. Long, C. Zeng, M. Ma, Y. Hong, H. Xu, J. Xu, A cascading flash flood guidance system: development and application in Yunnan Province, China, Nat. Hazards. 84 (2016) 20712093. https://doi.org/10.1007/s11069-016-2535-2.

[11] B. Büchele, H. Kreibich, A. Kron, A. Thieken, J. Ihringer, P. Oberle, B. Merz, F. Nestmann, Flood- 
risk mapping: Contributions towards an enhanced assessment of extreme events and associated risks, Nat. Hazards Earth Syst. Sci. 6 (2006) 483-503. https://doi.org/10.5194/nhess-6-485-2006.

[12] Z. Xiang, J. Yan, I. Demir, A Rainfall-Runoff Model With LSTM-Based Sequence-to-Sequence Learning, Water Resour. Res. 56 (2020). https://doi.org/10.1029/2019WR025326.

[13] FEMA, Guidelines and Specifications for Flood Hazard Mapping Partners, 2003.

[14] I. Haltas, S. Elçi, G. Tayfur, Numerical Simulation of Flood Wave Propagation in Two-Dimensions in Densely Populated Urban Areas due to Dam Break, Water Resour. Manag. 30 (2016) 56995721. https://doi.org/10.1007/s11269-016-1344-4.

[15] I. Haltas, G. Tayfur, S. Elci, Two-dimensional numerical modeling of flood wave propagation in an urban area due to Ürkmez dam-break, İzmir, Turkey, Nat. Hazards. 81 (2016) 2103-2119. https://doi.org/10.1007/s11069-016-2175-6.

[16] D.R. Archer, H.J. Fowler, Characterising flash flood response to intense rainfall and impacts using historical information and gauged data in Britain, J. Flood Risk Manag. 11 (2018) S121-S133. https://doi.org/10.1111/jfr3.12187.

[17] S.N. Jonkman, J.K. Vrijling, Loss of life due to floods, J. Flood Risk Manag. 1 (2008) 43-56. https://doi.org/10.1111/j.1753-318X.2008.00006.x.

[18] J.J. Gourley, Y. Hong, Z.L. Flamig, A. Arthur, R. Clark, M. Calianno, I. Ruin, T. Ortel, M.E. Wieczorek, P.E. Kirstetter, E. Clark, W.F. Krajewski, A unified flash flood database across the United States, Bull. Am. Meteorol. Soc. (2013). https://doi.org/10.1175/BAMS-D-12-00198.1.

[19] G. Koç, A.H. Thieken, Societal and economic impacts of flood hazards in Turkey - an overview, E3S Web Conf. 7 (2016) 05012. https://doi.org/10.1051/e3sconf/20160705012.

[20] F. Guzzetti, C.P. Stark, P. Salvati, Evaluation of Flood and Landslide Risk to the Population of Italy, Environ. Manage. 36 (2005) 15-36. https://doi.org/10.1007/s00267-003-0257-1.

[21] A.M. Youssef, B. Pradhan, S.A. Sefry, Flash flood susceptibility assessment in Jeddah city (Kingdom of Saudi Arabia) using bivariate and multivariate statistical models, Environ. Earth Sci. 75 (2016) 1-16. https://doi.org/10.1007/s12665-015-4830-8.

[22] W.T.L. Chow, B.D. Cheong, B.H. Ho, A Multimethod Approach towards Assessing Urban Flood Patterns and Its Associated Vulnerabilities in Singapore, Adv. Meteorol. 2016 (2016) 1-11. https://doi.org/10.1155/2016/7159132.

[23] D.F. Laefer, A. Koss, A. Pradhan, The need for baseline data characteristics for GIS-based disaster management systems, J. Urban Plan. Dev. (2006). https://doi.org/10.1061/(ASCE)07339488(2006)132:3(115).

[24] M.W. Downton, R.A. Pielke, How accurate are disaster loss data? The case of U.S. flood damage, Nat. Hazards. (2005). https://doi.org/10.1007/s11069-004-4808-4.

[25] S.L. Cutter, J.T. Mitchell, M.S. Scott, Revealing the vulnerability of people and places: A case study of georgetown county, South Carolina, Ann. Assoc. Am. Geogr. (2000).

https://doi.org/10.1111/0004-5608.00219.

[26] E. Gaume, V. Bain, P. Bernardara, O. Newinger, M. Barbuc, A. Bateman, L. Blaškovičová, G. Blöschl, M. Borga, A. Dumitrescu, I. Daliakopoulos, J. Garcia, A. Irimescu, S. Kohnova, A. Koutroulis, L. Marchi, S. Matreata, V. Medina, E. Preciso, D. Sempere-Torres, G. Stancalie, J. Szolgay, I. Tsanis, D. Velasco, A. Viglione, A compilation of data on European flash floods, J. 
Hydrol. 367 (2009) 70-78. https://doi.org/10.1016/j.jhydrol.2008.12.028.

[27] T. Tingsanchali, Urban flood disaster management, in: Procedia Eng., 2012. https://doi.org/10.1016/j.proeng.2012.01.1233.

[28] J.I. Barredo, Major flood disasters in Europe: 1950-2005, Nat. Hazards. 42 (2007) 125-148. https://doi.org/10.1007/s11069-006-9065-2.

[29] K.P. Holz, G. Hildebrandt, L. Weber, Concept for a web-based information system for flood management, Nat. Hazards. (2006). https://doi.org/10.1007/s11069-005-8605-5.

[30] E. Yildirim, I. Demir, An integrated web framework for HAZUS-MH flood loss estimation analysis, Nat. Hazards. (2019). https://doi.org/10.1007/s11069-019-03738-6.

[31] R. Agliamzanov, M. Sit, I. Demir, Hydrology@Home: a distributed volunteer computing framework for hydrological research and applications, J. Hydroinformatics. 22 (2020) 235-248. https://doi.org/10.2166/hydro.2019.170.

[32] I. Demir, E. Yildirim, Y. Sermet, M.A. Sit, FLOODSS: lowa flood information system as a generalized flood cyberinfrastructure, Int. J. River Basin Manag. (2018). https://doi.org/10.1080/15715124.2017.1411927.

[33] E. Yildirim, Hazus-MH Flood Loss Estimation on a Web-Based System, 2017.

[34] Y. Sermet, I. Demir, An intelligent system on knowledge generation and communication about flooding, Environ. Model. Softw. (2018). https://doi.org/10.1016/j.envsoft.2018.06.003.

[35] Y. Sermet, I. Demir, Towards an information centric flood ontology for information management and communication, Earth Sci. Informatics. 12 (2019) 541-551. https://doi.org/10.1007/s12145019-00398-9.

[36] Y. Sermet, I. Demir, M. Muste, A serious gaming framework for decision support on hydrological hazards, Sci. Total Environ. (2020). https://doi.org/10.1016/j.scitotenv.2020.138895.

[37] A. Carson, M. Windsor, H. Hill, T. Haigh, N. Wall, J. Smith, R. Olsen, D. Bathke, I. Demir, M. Muste, Serious gaming for participatory planning of multi-hazard mitigation, Int. J. River Basin Manag. (2018). https://doi.org/10.1080/15715124.2018.1481079.

[38] H. Xu, M. Windsor, M. Muste, I. Demir, A web-based decision support system for collaborative mitigation of multiple water-related hazards using serious gaming, J. Environ. Manage. 255 (2020) 109887. https://doi.org/10.1016/j.jenvman.2019.109887.

[39] D. Guha-Sapir, R. Below, The Quality and Accuracy of Disaster Data: A comparative analyses of three Global Data Sets, 2002.

[40] P. Ebert-Uphoff, I., Thompson, D.R., Demir, I., Gel, Y.R., Karpatne, A., Guereque, M., Kumar, V., Cabral-Cano, E. and Smyth, A vision for the development of benchmarks to bridge geoscience and data science, in: 17th Int. Work. Clim. Informatics, 2017.

[41] I. Demir, R. Szczepanek, Optimization of river network representation data models for web-based systems, Earth Sp. Sci. (2017). https://doi.org/10.1002/2016EA000224.

[42] Y. Sermet, P. Villanueva, M.A. Sit, I. Demir, Crowdsourced approaches for stage measurements at ungauged locations using smartphones, Hydrol. Sci. J. (2020). https://doi.org/10.1080/02626667.2019.1659508.

[43] M. Sit, Y. Sermet, I. Demir, Optimized watershed delineation library for server-side and client-side 
web applications, Open Geospatial Data, Softw. Stand. 4 (2019) 8.

https://doi.org/10.1186/s40965-019-0068-9.

[44] Z. Xiang, I. Demir, Distributed long-term hourly streamflow predictions using deep learning - A case study for State of lowa, Environ. Model. Softw. (2020). https://doi.org/10.1016/j.envsoft.2020.104761.

[45] B. Hornbuckle, V. Walker, B. Eichinger, V. Wallace, E. Yildirim, Soil surface roughness observed during SMAPVEX16-IA and its potential consequences for SMOS and SMAP, in: Int. Geosci. Remote Sens. Symp., 2017. https://doi.org/10.1109/IGARSS.2017.8127379.

[46] M. Sit, I. Demir, Decentralized Flood Forecasting Using Deep Neural Networks, (2019). http://arxiv.org/abs/1902.02308.

[47] A. Mansourian, A. Rajabifard, M.J. Valadan Zoej, I. Williamson, Using SDI and web-based system to facilitate disaster management, Comput. Geosci. (2006). https://doi.org/10.1016/j.cageo.2005.06.017.

[48] L. Alfieri, S. Cohen, J. Galantowicz, G.J.P. Schumann, M.A. Trigg, E. Zsoter, C. Prudhomme, A. Kruczkiewicz, E. Coughlan de Perez, Z. Flamig, R. Rudari, H. Wu, R.F. Adler, R.G. Brakenridge, A. Kettner, A. Weerts, P. Matgen, S.A.K.M. Islam, T. de Groeve, P. Salamon, A global network for operational flood risk reduction, Environ. Sci. Policy. (2018).

https://doi.org/10.1016/j.envsci.2018.03.014.

[49] P. Adhikari, Y. Hong, K.R. Douglas, D.B. Kirschbaum, J. Gourley, R. Adler, G. Robert Brakenridge, A digitized global flood inventory (1998-2008): compilation and preliminary results, Nat. Hazards. 55 (2010) 405-422. https://doi.org/10.1007/s11069-010-9537-2.

[50] I. Demir, W.F. Krajewski, Towards an integrated Flood Information System: Centralized data access, analysis, and visualization, Environ. Model. Softw. (2013). https://doi.org/10.1016/j.envsoft.2013.08.009.

[51] I. Haltas, I. Demir, Toward a Flood Information System (TABiS) for Turkey, in: 11th Int. Conf. Hydroinformatics, CUNY Academic Works, New York City, USA, 2014. https://academicworks.cuny.edu/cc_conf_hic/432.

[52] Y. Sermet, I. Demir, Flood action VR: A virtual reality framework for disaster awareness and emergency response training, in: ACM SIGGRAPH 2019 Posters, SIGGRAPH 2019, 2019. https://doi.org/10.1145/3306214.3338550.

[53] I. Gurer, H. Ozguler, Turkey: Recent Flood Disasters in Northwestern Black Sea Region, 2004.

[54] G. Koç, A. Thieken, Flood hazards and impacts in Turkey - an overview, in: 3rd Eur. Conf. Flood Risk Manag., 2016.

[55] B.B.B. Erkan, E. Hasgul, Turkish Disaster Data Bank (TABB), in: 7th Int. Conf. Seismol. Earthq. Eng., International Institute of Earthquake Engineering and Seismology (IIEES), 2015: pp. 441-442. http://www.iiees.ac.ir/fa/wp-content/uploads/2016/04/00019-RL.pdf.

[56] I. Gürer, I. Uçar, Flood Disasters' Inventory in Turkey in 2009, in: Elev. Int. Symp. Water Manag. Hydraul. Eng., Ohrid, Macedonia, 2009: pp. 371-380.

[57] Centre for Research on the Epidemiology of Disasters (CRED), EM-DAT The International Disaster Database, (n.d.). https://www.emdat.be/.

[58] G.R. Brakenridge, Global Active Archive of Large Flood Events, Dartmouth Flood Observatory, 
University of Colorado, (n.d.). http://floodobservatory.colorado.edu/Archives/index.html.

[59] Asian Disaster Reduction Centre, GLobal IDEntifier Number (GLIDE), (n.d.). https://glidenumber.net/glide/public/about.jsp.

[60] D. Paprotny, O. Morales-Nápoles, S.N. Jonkman, HANZE: A pan-European database of exposure to natural hazards and damaging historical floods since 1870, Earth Syst. Sci. Data. (2018). https://doi.org/10.5194/essd-10-565-2018.

[61] CEMHS, The Spatial Hazard Events and Losses Database for the United States, Version 18.1 [Online Database] Phoenix, AZ: Arizona State University, (2020). http://www.sheldus.org.

[62] M. Diakakis, S. Mavroulis, G. Deligiannakis, Floods in Greece, a statistical and spatial approach, Nat. Hazards. 62 (2012) 485-500. https://doi.org/10.1007/s11069-012-0090-z. 


\section{Appendix}

Table A1. Data field matrix of the proposed specification and existing databases

\begin{tabular}{|c|c|c|c|c|c|c|c|c|c|c|}
\hline Category & Data Fields & FEDS & EM-DAT & DFO & TABB & MGM & HANZE & Munich Re & SHELDUS & GLIDE \\
\hline \multirow{8}{*}{ 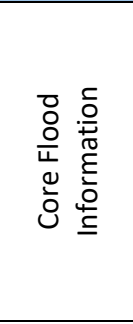 } & Flood Event ID & yes & yes & yes & yes & no & yes & yes & yes & yes \\
\hline & Flood Event Code & yes & no & no & no & no & no & no & no & no \\
\hline & GLIDE Number & yes & yes & yes & yes & yes & yes & yes & yes & yes \\
\hline & \begin{tabular}{|l|} 
Event Date \\
\end{tabular} & yes & yes & yes & yes & yes & yes & yes & yes & yes \\
\hline & City & yes & no & yes & yes & yes & no & yes & yes & yes \\
\hline & State & yes & yes & yes & no & no & yes & yes & yes & yes \\
\hline & Country & yes & yes & yes & no & no & yes & yes & yes & yes \\
\hline & Flooding Type & yes & yes & no & no & yes & yes & no & yes & no \\
\hline \multirow{4}{*}{ 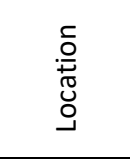 } & District & yes & yes & no & no & yes & yes & no & yes & no \\
\hline & Vicinity & yes & no & no & no & no & yes & no & no & no \\
\hline & Area (Geometry) & yes & no & no & no & no & no & no & no & no \\
\hline & \begin{tabular}{|l} 
Location (Geometry) \\
\end{tabular} & yes & yes & yes & yes & yes & yes & yes & yes & yes \\
\hline \multirow{5}{*}{ 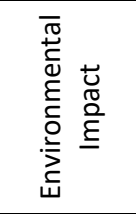 } & Water Quality & yes & no & no & no & no & no & no & no & no \\
\hline & Soil Contamination & yes & no & no & no & no & yes & no & no & no \\
\hline & Soil Loss / Erosion & yes & yes & yes & no & no & no & no & no & no \\
\hline & Landslide & yes & yes & no & no & no & no & no & no & yes \\
\hline & Habitat & yes & no & no & no & no & no & no & no & no \\
\hline \multirow{6}{*}{ 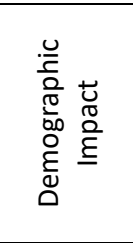 } & Fatality & yes & no & yes & yes & no & yes & yes & yes & no \\
\hline & Injured & yes & no & no & yes & no & no & no & yes & no \\
\hline & Missing & yes & no & no & yes & no & no & no & no & no \\
\hline & \begin{tabular}{|l|} 
Indirect Affected \\
\end{tabular} & yes & no & yes & yes & no & yes & no & no & no \\
\hline & \begin{tabular}{|l|} 
Displaced \\
\end{tabular} & yes & no & yes & yes & no & no & no & no & no \\
\hline & Evacuated & yes & no & no & yes & no & no & no & no & no \\
\hline \multirow{16}{*}{ 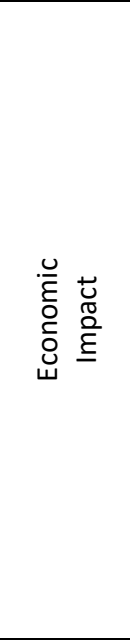 } & Destroyed Property & yes & no & no & yes & no & no & no & no & no \\
\hline & \begin{tabular}{|l|} 
Total Damaged Buildings \\
\end{tabular} & yes & no & no & yes & no & no & no & no & no \\
\hline & Flooded Residential & yes & no & no & yes & no & no & no & no & no \\
\hline & Flooded Business & yes & no & no & no & no & no & no & no & no \\
\hline & Flooded Public & yes & no & no & no & no & no & no & no & no \\
\hline & Flooded Vehicles & yes & no & no & yes & no & no & no & no & no \\
\hline & \begin{tabular}{|l|} 
Perished Cattle \\
\end{tabular} & yes & no & no & yes & no & no & no & no & no \\
\hline & Perished Ovine & yes & no & no & yes & no & no & no & no & no \\
\hline & \begin{tabular}{|l|} 
Perished Poultry \\
\end{tabular} & yes & no & no & yes & no & no & no & no & no \\
\hline & Flooded Agricultural Land & yes & no & no & yes & no & no & no & yes & no \\
\hline & Damaged Infrastructure & yes & no & no & yes & no & no & no & no & no \\
\hline & \begin{tabular}{|l|l} 
Total Direct Economic Loss \\
\end{tabular} & yes & no & no & yes & no & yes & yes & yes & no \\
\hline & \begin{tabular}{|l|} 
Direct Residential Loss \\
\end{tabular} & yes & no & yes & yes & no & no & no & no & no \\
\hline & Direct Business Loss & yes & no & no & yes & no & no & no & no & no \\
\hline & \begin{tabular}{|l} 
Direct Agricultural Loss \\
\end{tabular} & yes & no & yes & yes & no & no & no & yes & no \\
\hline & Direct Public Loss & yes & no & no & yes & no & no & no & no & no \\
\hline \multirow{12}{*}{ 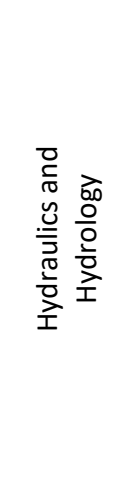 } & Duration & yes & no & yes & no & no & no & no & yes & yes \\
\hline & Velocity & yes & no & no & no & no & no & no & no & no \\
\hline & \begin{tabular}{|l|} 
Triggering Factor \\
\end{tabular} & yes & no & no & no & no & no & no & no & no \\
\hline & Frequency & yes & yes & yes & no & no & no & no & no & yes \\
\hline & Intensity & yes & no & no & no & no & no & no & no & no \\
\hline & Flooded River & yes & no & no & no & no & yes & no & no & no \\
\hline & Flood Extent Map & yes & no & no & no & no & no & no & no & no \\
\hline & Flood Depth Map & yes & no & no & no & no & no & no & no & no \\
\hline & Flood Velocity Map & yes & no & no & no & no & no & no & no & no \\
\hline & \begin{tabular}{|l|} 
Reference Point \\
\end{tabular} & yes & no & no & no & no & no & no & no & no \\
\hline & \begin{tabular}{|l|} 
Peak Discharge \\
\end{tabular} & yes & no & no & no & no & no & no & no & no \\
\hline & Peak Discharge (date/time) & yes & no & no & no & no & no & no & no & no \\
\hline
\end{tabular}




\begin{tabular}{|c|c|c|c|c|c|c|c|c|c|c|}
\hline & Peak Water Level & yes & no & no & no & no & no & no & no & no \\
\hline & $\begin{array}{l}\text { Peak Water Level } \\
\text { (date/time) }\end{array}$ & yes & no & no & no & no & no & no & no & no \\
\hline & Station Location (Geometry) & yes & no & no & no & no & no & no & no & no \\
\hline \multirow{5}{*}{ 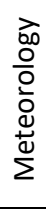 } & Reference Station & yes & no & no & no & no & no & no & no & no \\
\hline & Station Location (Geometry) & yes & no & no & no & no & no & no & no & no \\
\hline & Total Precipitation & yes & no & no & no & yes & no & no & no & no \\
\hline & Precipitation Duration & yes & no & no & no & yes & no & no & no & no \\
\hline & Total Precipitation Map & yes & no & no & no & no & no & no & no & no \\
\hline \multirow{6}{*}{ 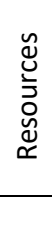 } & Resource ID & yes & no & no & no & no & no & no & no & no \\
\hline & Type & yes & no & no & no & no & no & no & no & no \\
\hline & Website & yes & no & no & no & no & yes & no & no & yes \\
\hline & File & yes & no & no & no & no & no & no & no & no \\
\hline & Event Description & yes & no & yes & no & yes & no & no & yes & no \\
\hline & Number of Attributes & 64 & 11 & 16 & 25 & 9 & 15 & 9 & 16 & 11 \\
\hline
\end{tabular}


Table A2. Details of attributes for specification tables of the proposed database

\begin{tabular}{|c|c|c|c|c|c|}
\hline Category & Field Name & Required & Format & Unit & Description \\
\hline \multirow{8}{*}{ 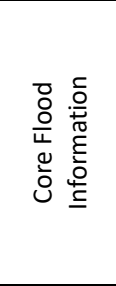 } & Flood Event ID & yes (auto) & integer & - & Assigned automatically for internal use in DB \\
\hline & Flood Event Code & yes (auto) & text & - & Assigned automatically for external use \\
\hline & GLIDE Number & yes (auto) & text & - & Assigned automatically from GLIDE ID system \\
\hline & City & yes & text & - & Impacted communities \\
\hline & State & yes & text & - & Regions larger than city (i.e. state or province) \\
\hline & Country & yes & text & - & Country of the impacted community \\
\hline & Flood Type & yes & text & - & Riverine, urban, coastal, flash \\
\hline & Event Date & yes & date & - & Start date \\
\hline \multirow{4}{*}{$\underset{\substack{0 \\
\stackrel{0}{0}}}{\stackrel{ }{0}}$} & District & optional & text & - & Regions smaller than a province or state \\
\hline & Vicinity & optional & text & - & Area near or surrounding impacted region \\
\hline & Area & optional & $\begin{array}{l}\text { geometry } \\
\text { (polygon) }\end{array}$ & - & Boundary affected by flooding \\
\hline & Location & yes (auto) & $\begin{array}{l}\text { geometry } \\
\text { (point) }\end{array}$ & - & Hybrid / user provided or auto generated by best location info \\
\hline \multirow{5}{*}{ 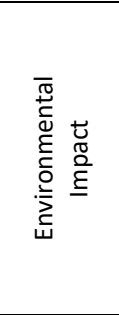 } & Water Quality & optional & text & - & $\begin{array}{l}\text { Accumulated animal waste, salt, pesticide or oil in water resources if } \\
\text { any observed in the vicinity of the flood event }\end{array}$ \\
\hline & $\begin{array}{l}\text { Soil } \\
\text { Contamination } \\
\end{array}$ & optional & text & - & $\begin{array}{l}\text { Anaerobic conditions and carried contaminants by floods lead soil } \\
\text { contamination if any observed in the vicinity of the flood event }\end{array}$ \\
\hline & \begin{tabular}{|l|} 
Soil Loss / \\
Erosion
\end{tabular} & optional & text & - & If soil erosion is observed in the vicinity of the flood event \\
\hline & Land Slide & optional & text & - & If large portion of soil is removed in the vicinity of the flood event \\
\hline & Habitat & optional & text & - & $\begin{array}{l}\text { If any certain wild animal or plant species is particularly impacted in } \\
\text { the vicinity of the flood event }\end{array}$ \\
\hline \multirow{6}{*}{ 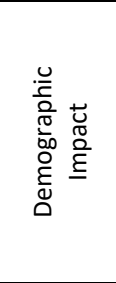 } & Fatalities & optional & integer & - & Number of dead people due to flood event \\
\hline & Injured & optional & integer & - & Number of injured people due to flood event \\
\hline & Missing / Lost & optional & integer & - & Number of missing people due to flood event \\
\hline & $\begin{array}{l}\text { Indirectly } \\
\text { Affected }\end{array}$ & optional & integer & - & $\begin{array}{l}\text { Number of affected people who only experienced life disruption not } \\
\text { displaced or evacuated due to flood event }\end{array}$ \\
\hline & Displaced & optional & integer & - & $\begin{array}{l}\text { Number of permanently or long-term displaced people due to flood } \\
\text { event }\end{array}$ \\
\hline & Evacuated & optional & integer & - & Number of evacuated people for safety measures due to flood event \\
\hline \multirow{16}{*}{ 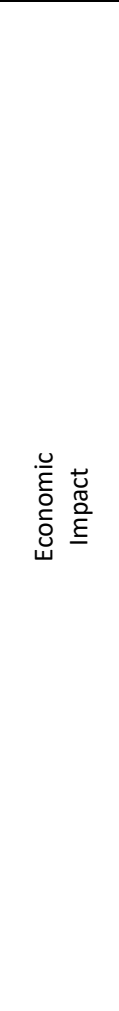 } & $\begin{array}{l}\text { Destroyed } \\
\text { Property }\end{array}$ & optional & integer & - & Number of building that total loss \\
\hline & $\begin{array}{l}\text { Total Damaged } \\
\text { Buildings } \\
\end{array}$ & optional & integer & - & $\begin{array}{l}\text { Number of building that experienced structural or content losses due } \\
\text { to flood event }\end{array}$ \\
\hline & \begin{tabular}{|l|} 
Flooded \\
Residential \\
\end{tabular} & optional & integer & - & Number of residential buildings impacted by a flood event \\
\hline & Flooded Business & optional & integer & - & $\begin{array}{l}\text { Number of commercial or industrial buildings impacted by a flood } \\
\text { event }\end{array}$ \\
\hline & \begin{tabular}{|l} 
Flooded Public \\
Buildings \\
\end{tabular} & optional & integer & - & Number of public buildings impacted by a flood event \\
\hline & Flooded Vehicles & optional & integer & - & Number of vehicles impacted by a flood event \\
\hline & $\begin{array}{l}\text { Flooded } \\
\text { Agricultural Land }\end{array}$ & optional & numeric & square km & Impacted square kilometers of agricultural land \\
\hline & Perished Cattle & optional & integer & - & Number of cattle perished due to the flood event \\
\hline & Perished Ovine & optional & integer & - & Number of ovine perished due to the flood event \\
\hline & Perished Poultry & optional & integer & - & Number of poultry perished due to the flood event \\
\hline & \begin{tabular}{|l|} 
Damaged \\
Infrastructure \\
\end{tabular} & optional & text & - & $\begin{array}{l}\text { Report impacted infrastructure if any (i.e. sewage, pavement, road, } \\
\text { bridge) }\end{array}$ \\
\hline & $\begin{array}{l}\text { Total Direct } \\
\text { Economic Loss }\end{array}$ & optional & numeric & $\begin{array}{l}\text { local } \\
\text { currency }\end{array}$ & $\begin{array}{l}\text { Structural and content combined direct economic losses from } \\
\text { residential, commercial, industrial, government buildings, and } \\
\text { agricultural lands }\end{array}$ \\
\hline & $\begin{array}{l}\text { Direct } \\
\text { Residential Loss }\end{array}$ & optional & numeric & $\begin{array}{l}\text { local } \\
\text { currency }\end{array}$ & $\begin{array}{l}\text { Structural and content combined direct economic losses from } \\
\text { residential }\end{array}$ \\
\hline & $\begin{array}{l}\text { Direct Business } \\
\text { Loss }\end{array}$ & optional & numeric & $\begin{array}{l}\text { local } \\
\text { currency }\end{array}$ & $\begin{array}{l}\text { Structural and content combined direct economic losses from } \\
\text { commercial and industrial buildings }\end{array}$ \\
\hline & $\begin{array}{l}\text { Direct } \\
\text { Agricultural Loss } \\
\end{array}$ & optional & numeric & $\begin{array}{l}\text { local } \\
\text { currency }\end{array}$ & Direct economic losses of agricultural land \\
\hline & Direct Public Loss & optional & numeric & $\begin{array}{l}\text { local } \\
\text { currency }\end{array}$ & $\begin{array}{l}\text { Structural and content combined direct economic losses from } \\
\text { government buildings }\end{array}$ \\
\hline
\end{tabular}




\begin{tabular}{|c|c|c|c|c|c|}
\hline \multirow{15}{*}{ 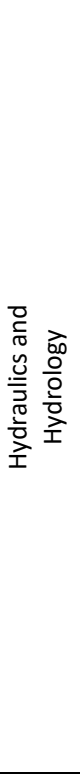 } & Duration & optional & numeric & hours & The time span between the start and end of the flooding \\
\hline & Flow Velocity & optional & numeric & $\mathrm{m} / \mathrm{s}$ & Observed peak flow velocity in the flooded river \\
\hline & Triggering Factor & optional & text & - & $\begin{array}{l}\text { Main cause for flood event such snow melt, dam break, heavy } \\
\text { precipitation }\end{array}$ \\
\hline & Frequency & optional & years & - & Return Period \\
\hline & Intensity & optional & text & - & $\begin{array}{l}\text { It can be characterized by depth of inundation, volume of inundation, } \\
\text { velocity of flow and rate of rise of water. }\end{array}$ \\
\hline & Flooded River & optional & text & - & The name of the flooded river \\
\hline & $\begin{array}{l}\text { Flood Extent } \\
\text { Map }\end{array}$ & optional & $\begin{array}{l}\text { geometry } \\
\text { (polygon) }\end{array}$ & - & Boundaries for the inundated area \\
\hline & Flood Depth Map & optional & raster & - & Depth map in the inundated area \\
\hline & $\begin{array}{l}\text { Flood Velocity } \\
\text { Map }\end{array}$ & optional & raster & - & Velocity map in the inundated area \\
\hline & Reference Point & optional & text & - & Station name \\
\hline & Peak Discharge & optional & numeric & $\mathrm{cms}$ & Highest observed discharge in cubic meter \\
\hline & $\begin{array}{l}\text { Peak Discharge } \\
\text { Time }\end{array}$ & optional & $\begin{array}{l}\text { time } \\
\text { stamp }\end{array}$ & - & Date and time for the measurement \\
\hline & Peak Water Level & optional & numeric & meter & Highest observed water level in meter \\
\hline & $\begin{array}{l}\text { Peak Water Level } \\
\text { Time }\end{array}$ & optional & $\begin{array}{l}\text { time } \\
\text { stamp }\end{array}$ & - & Date and time for the measurement \\
\hline & Station Location & optional & $\begin{array}{l}\text { geometry } \\
\text { (point) }\end{array}$ & - & Hybrid / user provided or auto generated by best location info \\
\hline \multirow{5}{*}{ 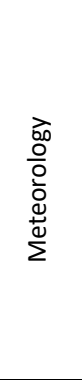 } & \begin{tabular}{|l|} 
Reference \\
Station \\
\end{tabular} & optional & text & - & Station name \\
\hline & Station Location & optional & $\begin{array}{l}\text { geometry } \\
\text { (point) }\end{array}$ & - & Hybrid / user provided or auto generated by best location info \\
\hline & \begin{tabular}{|l|} 
Total \\
Precipitation \\
\end{tabular} & optional & numeric & $\mathrm{mm}$ & Measured rainfall during the flood event in $\mathrm{mm}$ \\
\hline & $\begin{array}{l}\text { Precipitation } \\
\text { Duration }\end{array}$ & optional & numeric & hour & Duration of the rainfall during the flood event \\
\hline & \begin{tabular}{|l} 
Total \\
Precipitation \\
Map \\
\end{tabular} & optional & raster & - & Precipitation measurement from a radar instrument \\
\hline \multirow{5}{*}{ 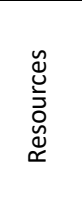 } & Resource ID & yes (auto) & integer & - & Assigned automatically for internal use in DB \\
\hline & Type & optional & text & - & $\begin{array}{l}\text { Supported media types listed (journal article, technical report, data, } \\
\text { photo, video, news, ...) }\end{array}$ \\
\hline & Website & optional & text & - & Reference link for the event from a website \\
\hline & File & optional & text & - & Digital file for the resource \\
\hline & Description & optional & text & - & Reference info and description of the resource \\
\hline
\end{tabular}

